\title{
Role of biomaterials in the diagnosis, prevention, treatment, and study of corona virus disease 2019 (COVID-19)
}

\author{
Yavuz Nuri Ertas ${ }^{1,2} \cdot$ Mahboobeh Mahmoodi $^{3,4} \cdot$ Fahimeh Shahabipour $^{5,6} \cdot$ Vahid Jahed $^{7} \cdot$ Sibel Emir Diltemiz ${ }^{8}$. \\ Rumeysa Tutar $^{9} \cdot$ Nureddin Ashammakhi $^{3,10}$ (1)
}

Received: 13 December 2020 / Accepted: 12 January 2021 / Published online: 16 March 2021

(C) Qatar University and Springer Nature Switzerland AG 2021

\begin{abstract}
Recently emerged novel severe acute respiratory syndrome coronavirus 2 (SARS-CoV-2) and the resulting corona virus disease 2019 (COVID-19) led to urgent search for methods to prevent and treat COVID-19. Among important disciplines that were mobilized is the biomaterials science and engineering. Biomaterials offer a range of possibilities to develop disease models, protective, diagnostic, therapeutic, monitoring measures, and vaccines. Among the most important contributions made so far from this field are tissue engineering, organoids, and organ-on-a-chip systems, which have been the important frontiers in developing tissue models for viral infection studies. Also, due to low bioavailability and limited circulation time of conventional antiviral drugs, controlled and targeted drug delivery could be applied alternatively. Fortunately, at the time of writing this paper, we have two successful vaccines and new at-home detection platforms. In this paper, we aim to review recent advances of biomaterial-based platforms for protection, diagnosis, vaccination, therapeutics, and monitoring of SARS-CoV-2 and discuss challenges and possible future research directions in this field.
\end{abstract}

Keywords Biomaterials · COVID-19 · SARS-2 · Organoid · Organ-on-a-chip · Tissue engineering

Nureddin Ashammakhi

n.ashammakhi@gmail.com

1 Department of Biomedical Engineering, Erciyes University, Kayseri, Turkey

2 ERNAM-Nanotechnology Research and Application Center, Erciyes University, Kayseri, Turkey

3 Department of Bioengineering, Henry Samueli School of Engineering, University of California, Los Angeles, CA, USA

4 Department of Biomedical Engineering, Yazd Branch, Islamic Azad University, Yazd, Iran

5 National Cell Bank of Iran, Pasteur Institute of Iran, Tehran, Iran

6 Skin Research Center, Shahid Beheshti University of Medical Science, Tehran, Iran

7 Biomedical Engineering Division, Faculty of Chemical Engineering, Tarbiat Modares University, Tehran, Iran

8 Department of Chemistry, Eskisehir Technical University, Eskisehir, Turkey

9 Department of Chemistry, Faculty of Engineering, Istanbul University-Cerrahpasa, Avcilar, Istanbul, Turkey

10 Department of Biomedical Engineering, College of Engineering, Michigan State University, East Lansing, MI, USA

\section{Introduction}

Infections may result in pandemics, and they had a major impact on human life and health throughout history [1]. Among important infections are those caused by viruses. Many of viral infections are now controlled through the development of appropriate prevention measures and vaccination programs [1]. Others still pose a major challenge, e.g., the recently emerged severe acute respiratory syndrome coronavirus 2 (SARS-CoV-2) which led to high mortality rates so far worldwide [2]. World Health Organization (WHO) has declared a pandemic just a few months after its emergence [1]. Our knowledge about this novel virus has been growing ever since, but it is still not enough. Besides, the possibility of spreading the SARS-CoV-2 from asymptomatic individuals makes it more important to develop a rapid and user-friendly diagnosis method. Critical need for new diagnostic and treatment approaches to stop its transmission should be considered. Regarding diagnostic platforms, development of rapid, precise, and lab-independent home-test point-of-care devices should be considered to quarantine infected people quickly and control the spread of the virus [3].

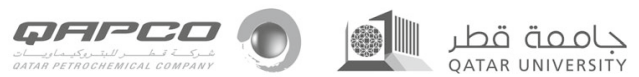


Thanks to intensive research, a vaccine that completed phase III clinical trials has recently been introduced [4]. There is, however, a long way to go to control this pandemic and treat new infections and possible accompanying complications of corona virus disease 2019 (COVID-19). This requires an interdisciplinary effort that involves various fields of science including biomaterials.

Biomaterials science can contribute to the development of new and efficient personal protective equipment, vaccines, drug delivery, and new therapeutics that can be used to prevent or treat SARS-CoV-2 infection, its sequelae, and complications. In addition, engineered tissues and cell culture models can have a major impact on investigating the disease, testing, and developing new therapeutic agents and vaccines [5]. This requires committed and sustained effort. Thus, biomaterials science can result in the design of a range of diagnostic and therapeutic tools for the management of COVID-19 that may include rapid and accurate diagnostic platforms, effective antiviral drugs, novel vaccines, and efficient laboratory models for assessing the infection $[1,6]$.

Therefore, in this review, we discuss reported results, current challenges and future directions.

\section{Applications/indications}

Biomaterials in their different forms and origins (synthetic or natural) have been explored for use in the diagnosis and management of COVID-19. Most of studies on the use of biomaterials were in the domain of the development of rapid, ultra-sensitive field-effect transistor (FET)-based biosensing, antiviral platforms, vaccines, and nano-based materials [7]. In the next sections, details of biomaterial application areas are given.

Earlier, most research in exploiting biomaterials for the treatment of infections has been devoted to fungi and bacteria. Further, with the rising prevalence of Middle East respiratory syndrome (MERS), influenza, and novel coronavirus, more virus-related research is required to be conducted [1]. In the recent COVID-19 outbreak, biosafety problems such as inadequate protective equipment, the lack of transportation equipment for infected patients, and difficulty in fast detection of virus have emerged as important challenges. In this regard, a wide variety of materials with unusual qualities to tackle the challenge of biosafety issues have been sought [8].

Protection (biosafety) materials Recently, the notion of biosafety materials has been suggested to produce materials that include disinfection, and detection of COVID-19 along with drug delivery systems [9]. In the COVID-19 pandemic, safety biomaterials are applied for protective equipment, such as protective clothing, masks, and goggles which are considered as important tools to contain the COVID-19 infection [10-13]. Various polymers including polypropylene [14], polyvinylidene fluoride (PVDF), and polytetrafluoroethylene (PTFE) have been utilized for the production of shields and face masks. In addition, polypropylene is used for the manufacturing masks such as FFP2, FFP3, N95, and surgical masks, while poly (ethylene terephthalate) (PET) and polycarbonate (PC) have been utilized in the face shields $[15,16]$.

\subsection{Biomaterials for studying COVID-19 and SARS- CoV-2 virus}

\subsubsection{Tissue engineering}

Tissue engineering provides engineering principles for biological applications [17], including the investigation of COVID19 [18-20]. Pertinent tissue engineering work in combating the Coronavirus can be categorized as in vitro models to evaluate the proposed treatment efficiency, drug delivery approaches, and vaccines [18]. Among various tissue engineering techniques, 3D bioprinting [21-23], organoid engineering $[24,25]$, and microfluidic organ-on-a-chip systems [26-28] are accepted to be the best approaches to design and develop effective in vitro tissue models [29].

Although several types of cells can be used for tissue engineering, stem cells represent an important source. In particular, pluripotent stem cells are of major importance because they are able to differentiate into different cell types [30]. Lately, induced pluripotent stem cells (iPSCs) were developed and they are important for generating personalized disease models [31] and can be utilized for investigating the pathogenesis of COVID-19 [32, 33]. For example, the use of 3D human lung organoid models that are derived from iPSCs were differentiated into the endodermal lung tissue to study the SARS-CoV-2 infection severity and infectivity [34]. The generation of lung models using pluripotent stem cells employs also biomaterials such as alginate, Matrigel, collagen, gelatin, poly dopamine, and hydrogels. For instance, Chen et al. created a 3D model of human lung by using human iPSCs (hiPSCs) of lung bud organoids, which were subsequently encapsulated in Matrigel and incubated afterwards [35]. After the solidification of Matrigel and the formation of branching airway and alveolar structure the lung disease model was then exposed to viral infection. In another study, Wilkinson et al. [36] generated a personalized lung disease model composed of iPSCs cultured on collagen I and polydopamine functionalized alginate beads to study the disease mechanism and drug testing. An electrostatic droplet generator was used to fabricate alginate beads and they were then soaked in high-concentration collagen I solution. 
In recent studies, mesenchymal stem cell (MSC)-based strategies have been used for treatment of viral infection [37]. MSCs contain specific cytokines that could be powerful in treating COVID-19 patients. MSCs can help to regenerate damaged tissues and prevent cytokine storm [19]. MSCs are ACE2-negative at the gene level and due to their immunomodulatory effect [38-40], anti-inflammatory properties [41, $42]$, and regenerative capacity $[43,44]$ can inhibit the release of unwanted cytokines [45]. Moreover, MSCs can reduce inflammation and acute lung injury induced by viral infections [46]. Therefore, MSCs can be a useful method for the treatment of COVID-19 [37, 47, 48]. Gardner et al. [49] used the rotation wall vessel bioreactor to evaluate the effect of low physiologic shear stresses as well as co-culturing human mesenchymal bronchial tracheal cells and bronchial epithelial cells on SARS-CoV-1. Their findings demonstrated that the complex 3D tissue-like aggregates formed in rotation wall vessel bioreactor to promote productive viral infection and physiological host responses. Ling et al. [50] cultured human pulmonary epithelial progenitor cells on a collagen matrix in combination with mesenchymal stroma as an in vitro model, and exposed them to SARS-CoV-1. In this study, it was shown that angiotensin-converting enzyme 2 (ACE-2) receptor, which is the target for SARS-CoV-1 infection can be expressed in in vitro models, and can be used to support active virus replication. MSCs also secrete extracellular vesicles (EVs) [51-53], which have immunomodulatory effect and they can be applied in the treatment of lung injury and inflammation [54]. EVs could be encapsulated in hydrogels and can be applied for anti-inflammatory therapeutic purposes $[55,56]$. Such research can be generalized to treat the acute respiratory syndrome resulting from infection by SARS-2 [57].

For the developments of a vaccination platform against pathogenic agents, the existence of antigens as well as specific elements that can stimulate the immune system should be considered, to enable being saved into memory cells [18]. Researchers may potentially use tissue engineering and biomaterials to stimulate host immune responses to develop strategies for vaccination [58], where the behavior of immune cells can be influenced by the size, shape, and physico-chemical properties of biomaterials [59, 60]. The motivation of using such systems is to target antigen-presenting cells and to stimulate specific immune response [18].

Several tissue-engineered in vitro human lung models have been introduced to study viral infection [61, 62]. But, these models must be developed further, and the 3D scaffolds should be fabricated to mimic native pulmonary architecture. Also, researchers should design the culture methods to allow the generation of extracellular matrix (ECM) before viral inoculation [18]. Tissue engineering can be used to develop a better understanding of the COVID-19 disease mechanisms and evaluating the effectiveness of drugs, antiviral agents
[63] and vaccines [64]. To provide an ideal tissue/organ model and exposure to virus is essential for the analysis of molecular pathways of COVID-19 pathogenesis and treatment . Also, design and fabrication of a 3D bioprinted multi-tissue platforms adapted for viral infection can be excellent tools for the study and development of treatment for COVID-19. 3D tissue models can be better than 2D models for studying COVID-19 due to their native tissue biomimicking characteristics [29]. 3D-engineered tissues can either be: (1) scaffoldbased or (2) scaffold-free using methods such as 3D bioprinting [65] and cell self-organization to produce spheroids and organoids [29]. In 3D bioprinting method, bioink composed of cell-laden hydrogels are deposited in a controlled fashion. The use of hydrogel-based scaffolds provides a 3D microenvironment for studying cell responses to viral infection and test drugs $[68,69]$. Hydrogels are usually used in bioink for 3D bioprinting and they include materials such as alginate, hyaluronic acid, fibrin, polyethylene glycol, gelatin, cellulose, and gelatin methacryloyl [70-74]. Accordingly, tissue engineering strategies can be useful tools to investigate the infection with SARS-CoV-2 and host-pathogen interactions. They require a multidisciplinary approach and offer the opportunity to develop novel ideas and methods to improve our knowledge, identify therapeutic targets, and develop novel drugs.

\subsubsection{Organoids (biomaterials-based)}

Organoids are clusters of organ-specific cells, such as those of the stomach, liver, intestine, and bladder [75]. They are derived from progenitor cells or stem cells, and they exhibit represented organ properties [75]. Cell self-organization techniques or 3D organoid cultures are effective models to investigate viral infection as well as possible interaction between host and pathogenic agents [76, 77]. Organoids have already been utilized to examine SARS-CoV-2 infection [78]. The results demonstrated that human recombinant soluble angiotensin-converting enzyme 2 (hrsACE2) can block SARS-CoV-2 infections [78, 79].

Hydrogel matrices were also used for organoid culture and supporting organoid growth [80]. There is a range of synthetic and natural hydrogels [81] that can potentially be used in organoid production. Synthetic hydrogels have generally higher mechanical strength than natural hydrogels, but they lack important bioactive moities needed to support cell adhesion and proliferation [82]. Natural hydrogels contain moities like arg-gly-asp (RGD) sequence and laminin that provide cell anchoring means and biological signals for organoid growth [81]. Synthetic hydrogels such as polyethylene glycol (PEG) [83], modified PEG using RGD and laminin [84], PEG-based hydrogels [85], alginate [86], hyaluronic acid, collagen, gelatin, and fibrin [81] can also be used to support the survival of organoids. 
The development of 3D organoids using bronchial transient epithelial cells that are usually attacked by SARS-CoV2, can be useful to study and understand COVID-19 [34]. Tindle et al. [25] created a complete adult stem cellderived lung organoid model. In vitro model was formed by adult lung organoids, primary airway cells, and humaninduced pluripotent stem cells (hiPSC)-derived alveolar type-II (AT2) pneumocytes. Organoids were immobilized on a Matrigel and infected with COVID-19 patient-derived respiratory sample. Figure 1a shows lung organoids that were grown in $3 \mathrm{D}$ cultures followed by single cell harvesting for creating 2D monolayer cultures to study infection by SARSCoV-2. In Fig. 1, primary airway epithelial cells and hiPSCderived alveolar type-II (AT2) pneumocytes are shown as in vitro lung models of SARS-CoV-2 infection. In step 4, transcriptomics datasets were applied to cross-validate SARS-CoV-2-infected ex vivo lung models of human COVID-19 autopsy lung specimens to objectively vet each model. In this study, researchers proved that the human lung model of COVID-19 could be employed for studying of COVID-19 pathogenesis, drug testing, and vaccine development. Also, their findings demonstrated that organoids have the potential to provide in vitro models with extra components such as immune and stromal cells in a physiologically related spatially segregated manner. Recently, Salahudeen et al. presented an approach based on organoids for modeling COVID19. To reach this goal, they used a 3D organoid in vitro model to simulate distal human lung in which basal stem cells and AT2 cells were cultured. After 26 days of culture, the lung organoid demonstrated the differentiation, and proliferation of different cell types including ACE2 receptor expressing cells

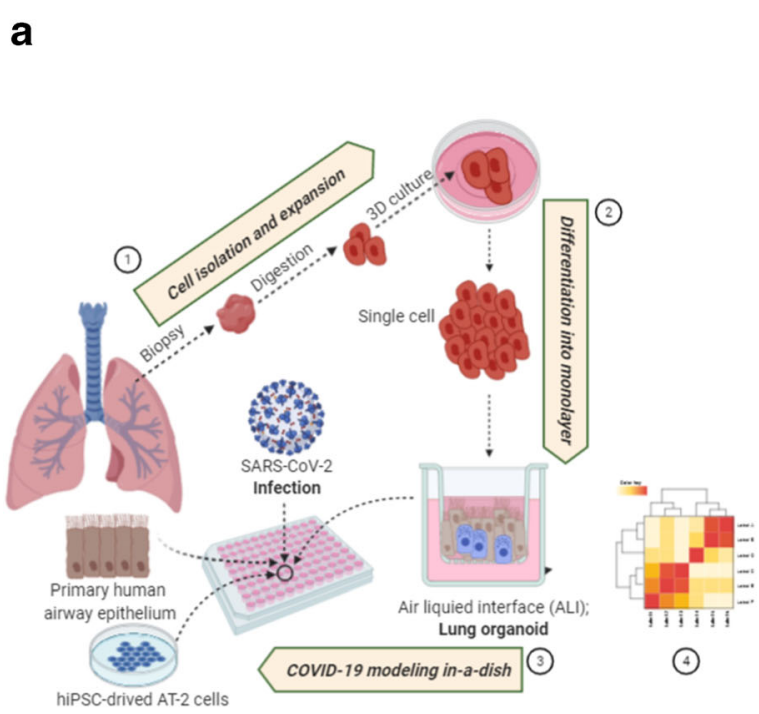

Fig. 1 Human organoid models for COVID-19 studies. a Schematic showing the procedure for creating lung organoids (steps 1 and 2), supplemented with proximal and distal airway components in-a-dish model of COVID-19 (step 3) and cross-validation of in vitro lung models of SARS-CoV-2 infection (step 4). Adapted from [25]. b Confocal
[88]. Further, Yang et al. designed an in vitro platform using hPSCs, islets, and hepatocyte cells through which they found a relation between diabetes and SARS-CoV-2 infection. For evaluation, the proposed organoids containing pancreatic cells, which were derived from hPSCs were transplanted into the kidneys of SCID mice. Cellular components were evaluated 2 months after xenograft transplantation using immunohistochemistry. Figure 1b shows the confocal microscopy images of the $\alpha$ and $\beta$ cells, as well as ACE2 receptors [80].

Researchers reported a model of pulmonary fibrosis for the evaluation of the effect of drugs on lung fibrosis. $3 \mathrm{D}$ in vitro tissue models were produced by using collagen hydrogels, decellularized fibroblast-derived and lung matrices, lung spheroids and organoids, and precise-cut slices of lung [89]. Mykytyn et al. [90] demonstrated the inhibition of SARS-CoV-2 entry to cells by hindering serine protease activity using drug camostat mesylate in an organoidderived human airway cells model. They seeded the organoid-derived human airway cells onto collagen-coated transwell to investigate the effect of the drug on SARSCoV-2. Porotto et al. [91] reported a 3D lung organoid derived from human pluripotent stem cells. Lung organoids were seeded on Matrigel to study human parainfluenza virus infection using an in vitro model. Accordingly, stem cellderived lung organoids can provide a useful model to study viral infection and host-pathogen interaction in the lung. In another study, Giobbe et al. [92] examined the susceptibility of the stomach to SARS-CoV-2 infection in gastric organoids model. In this study, gastric organoids were burried in Matrigel and infected with viral suspension to study the viral infection of the stomach. This gastric

b
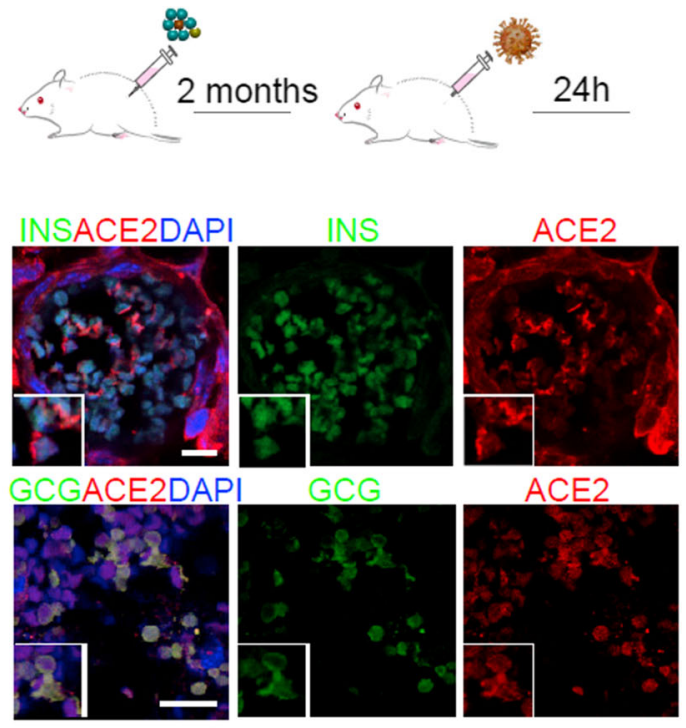

microscopy of immunohistochemistry, two months post-xenograft of hPSCs-derived pancreatic cells as in vitro model of COVID-19. In addition to alpha and beta cells, ACE2 receptors related to SARS-CoV-2 could be observed. Reproduced from [78] with permission from Elsevier 
organoid system provides a unique microenvironment to grow the virus and study gastric SARS-CoV-2 infection.

\subsubsection{Organ-on-a-Chip systems}

The assessment of enterovirus infection using animal models is limited due to the expression of different receptors in animals as compared to those in humans [93]. Also, the use of static cell culture systems do not imitate the natural complexity of the in vivo environment [94]. Therefore, testing of novel drug molecules and compounds using microfluidic organ-ona-chip $(\mathrm{OoC})$ systems can lead to results that can better anticipate clinical outcomes [95]. Microfluidic OoC systems present unparalleled opportunity to investigate various key molecular, biological, chemical, cellular, and mechanical parameters in a biomimetic microenvironment . OoC systems can recapitulate human organ physiology, disease states, and therapeutic responses to drugs with high accuracy $[96,97]$. Also, microfluidic-based 3D models and organ-on-a-chip systems provide biomimetic environment with air and fluid flows typical of what normally occurs in the lung, and can be useful for studying viral infection [29]. Therefore, the development of OoC-based technology to study the response of human tissues and organs to SARS-CoV-2 is urgently needed [98].

For example, gut-on-a-chip systems represent an attractive tool to study health and disease states [99], and they can be used to study SARS-CoV-2 infection. Recently, Guo et al. [98] reported the development of a SARS-CoV-2 infection in vitro using a biomimetic human intestine-on-a-chip device for studying of COVID-19. The intestine-on-a-chip device contained two parallel, cell culture microchannels, an upper epithelial cell-lined channel (co-cultured human intestinal epithelial cells and mucin secreting cells) and a lower vascular endothelial cell-lined channel separated by a thin flexible polydimethylsiloxane (PDMS) membrane which was coated with ECM. Thus, they provided a rapid and low-cost intestineon-chip infection model for studying human reaction to SARS-CoV-2 infection. In another application, Zhang et al. [100] created a biomimetic human disease model of SARSCoV-2-induced lung injury-on-a-chip and evaluated immune responses to viral infection. The chip device was coated with collagen type I and seeded with cells. They utilized this chip to study Remdesivir inhibitory effect on viral replication.

In another lung disease-on-a-chip model, Huh et al. investigated pulmonary edema [101]. They also used this model to study the effect of drug and mechanical breathing motions on pulmonary toxicity of IL-2 . In conclusion, latest progress in tissue engineering applied to COVID-19 demonstrates that mesenchymal stem cell therapy, exosomes, organoids, and on-chip disease models can be very useful for investigating SARS-CoV-2 viral infection, hostpathogen interaction, and testing drugs to treat COVID-19.

\subsection{Biomaterials for the diagnosis of COVID-19 infection}

Researchers have been working to develop rapid diagnostic approaches to help in stopping the spread of the COVID-19 infection. For the detection of target sequences related to SARS-CoV-2, real-time reverse-transcription polymerase chain reaction (RT-PCR) method has been widely employed as a reliable method for screening infected people.

Further, computed tomography (CT) scan of the chest is identified as another technique for rapid and reliable diagnosis of SARS-CoV-2 infection. Detection of interstitial changes and small patchy shadows in the lung may be a sign of the infection [102]. It was reported that CT confirmed $97 \%$ of patients with positive PCR, while positive chest $\mathrm{CT}$ was obtained for $75 \%$ of patients with negative PCR [103]. However, it was recommended that chest $\mathrm{CT}$ can be reserved for symptomatic and hospitalized patients, while PCR is the first-line tool to identify patients at the early stages of infection [104]. The limitations are $\mathrm{CT}$ scans include the need for high-quality imaging tools and skilled medical staff to accurately diagnose.

Immunoassay is another diagnostic technique that has been used to assess the levels of IgG and IgM in blood samples of patients who had SARS-CoV-2 infection. It is usually conducted by using enzyme-linked immunosorbent assays (ELISAs). Further, antibodies in plasmas can be donated to other infected patients [105]. However, ELISA is a timeconsuming approach due to several pre-test stages such as signal amplification and many washing steps that may cause an error [1]. Additionally, high antibody levels take several days to 3 weeks from the occurrence of first symptoms to appear, which is not acceptable as an early diagnostic method, [106].

To overcome these challenges, researchers have been working to develop a rapid, low-cost, reliable and portable device [107]. Alternatively, biomaterial-based tools have shown potential for use in virus detection $[6$, 107]. In the following section, point of care (POC) systems, their mechanism are introduced, and their potential use for the management of recent pandemic is discussed.

\subsubsection{Genetics- and biomaterial-based infection detectors}

The aim of genetics-based detection is the design of specific strategies for rapid diagnosis of target RNA/ DNA of the virus. Upon exposure, the interaction of the designed biomaterials and the target sequences leads to gene expression and cleave detectable reporter as a signal that can be measured using relatively simple devices. So far, several tools have emerged for this purpose and they can be adapted to the diagnosis of SARSCoV-2 infection. 


\subsubsection{Nanobiomaterial-based biosensors for the diagnosis of COVID-19}

Biomaterial-based strategies can be utilized in the development of biosensor-based diagnostics, which may provide an effective approach for rapid, and sensitive diagnosis [1]. In this regard, the application of nanoparticles for the isolation of either RNA or DNA from biological samples using magnetic field may be performed as an alternative method for rapid diagnosis. A further contribution of biomaterials field can be in the fabrication of nucleic acid biosensors, immunoassays for the assessment of viral antigens, and antibody detection, which enable enhanced COVID-19 detection in both symptomatic and asymptomatic infected individuals.

Nanomaterial-based biosensors are based on the use of specific binding as either singleplex or multiplex for diagnosis of infection [3]. The goal in designing biosensors is to develop a high-precision, rapid, low price, and portable platform that selectively binds to the target and reports the result as a signal. For instance, gold nanoparticles (AuNP) are widely used in diagnostic platforms due to their ability to electrostatically bind to antigen/antibody and present localized surface plasmon resonance shift [108]. In one study, Kim et al. reported the use of colorimetric readout bioassay focusing on the optical feature of AuNP via salt-induced aggregation for the diagnosis of Middle East respiratory syndrome coronavirus (MERS-CoV) in $10 \mathrm{~min}$ [109]. Similarly, Moitra et al. designed a platform based on the use of AuNP for nakedeye detection of SARS-CoV-2. As displayed in Fig. 2a, collected sample after RNA extraction is mixed with oligonucleotides (ASOs) capped AuNPs. In the presence of target RNA, RNA strand is separated from DNA/RNA hybrid by the addition of $\mathrm{RNaseH}$, followed by precipitation, which results in a change in color due to surface plasmon resonance [110].

Colloidal gold nanoparticle-based lateral flow strips (AuNP-LF) assay is a simple immunochromatographic strip platform made of cellulose membrane as carrier and anti-gene labeled colloidal gold nanoparticle as a tracer for detection of target antibody (Fig. 2b). Recently, AuNP-LF was employed for the detection of Influenza A and B virus [114], Rice stripe virus (RSV) [115], Newcastle disease virus (NDV) [116], H7N9 avian influenza virus [115], avian leukosis virus [117], and laryngotracheitis virus (ILTV) [118]. Following SARS-CoV-2 infection, IgM appears in blood samples a few days after the onset of initial symptoms. For this reason, Haung et al. produced a rapid platform based on the use of AuNP-LF for early detection of IgM, and the results were entirely consistent with PCR results [111]. Further, Zhang et al. fabricated a multiplexed assay based on AuNP-LF strategy for the detection of IgM and IgA against the Zika virus. The proposed structure is highly sensitive and it can be used with volumes as low as $1 \mu \mathrm{l}$ of human serum [119]. AuNP seems an accessible platform that makes it promising for the diagnosis of SARS-CoV-2, and it needs to be explored further. Recently, a rapid qualitative immunoassay based on the use AuNP-LF for the detection of IgM and IgG against SARSCoV-2 was commercialized [120].

Synthetic multi-component deoxyribozyme (MNAzyme) biosensors were introduced as another DNA detection technique. This platform is assembled on exposure to target sequences and then with the catalytic activity, leads to the production of a detectable reporter, which can then be read out $[121,122]$. It was reported that MNAzyme modification with a cationic copolymer could increase its selectivity and activity by $250-$ and 2700 -fold, respectively $[123,124]$. Considering the singleplex limitation mentioned earlier, Safdar et al. developed a multiplexed DNA detection platform based on the use of MNAzyme strategy [125].

One of the challenges in detecting SARS-CoV-2 is its mutation in some regions of the world during this pandemic. For example, it was reported that 382 nucleotides of the SARSCoV-2 genome had been deleted in Singapore, which was caused by false-negative reports when target sequences were defined based on deleted region [126]. Recently, singlemolecule nanopore (SMN) sequencing or third-generation platform was developed by Oxford Nanopore Technologies (ONT), which makes it possible to sequence long-size fragments of DNA/RNA [127]. SMN technique can detect changes in the nucleotides of DNA and RNA strand by passing them through a nanopore protein, which results in the production of a detectable electrical signal. Recently, SMN sequencing for detecting Hepatitis C [128], Hepatitis A [127], and Influenza virus A [129] were reported. However, because SMN is more time-consuming than other POC platforms, it is not currently considered a primary method for detecting SARS-CoV-2. Still, it can be applied for people who have a negative PCR test. Wang et al. employed the SMN technique for the diagnosis of SARS-CoV-2 infection, and the outcome was positive in 22 of 61 patients with suspected infection and negative PCR [126]. However, improvements still need to be made in the future.

\subsubsection{Label-free biomaterial-based biosensors}

As another platform, ultra-sensitive, label-free, and rapid nanowire field-effect transistor (NW-FET) devices provide an electrical platform for the detection of specific DNA sequences or a proteins. As shown in Fig. 2c, the change in the conductivity of antibody coated nanowires is due to the surface connection/disconnection of target molecules, leading to rapid analyte detection [112]. Cho et al. presented a platform based on the use of Silicon ( $\mathrm{Si}$ ) NW-FET to detect specific oligomers corresponding to the hepatitis $\mathrm{C}$ virus (HCV) [130]. Since the design of Si NW-FET has been proposed for detecting target sequences in the virus, DNA/RNA extraction followed by amplification should be performed before sample 
a

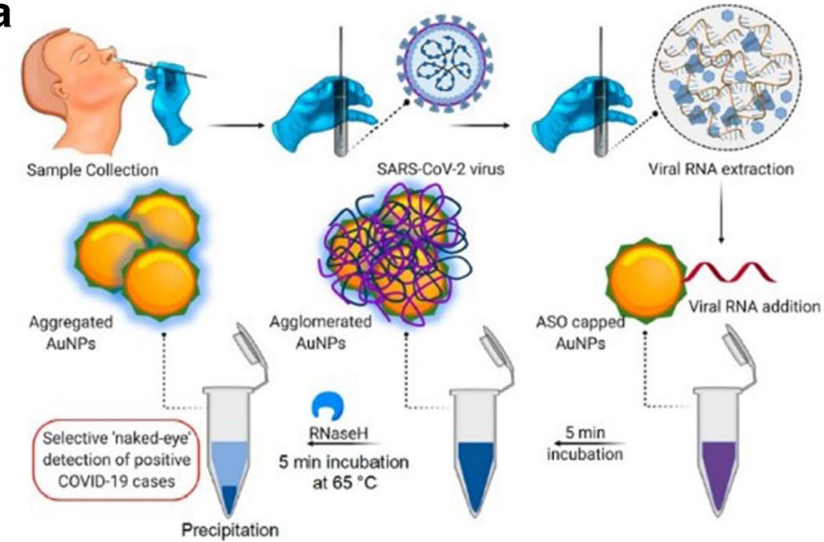

b

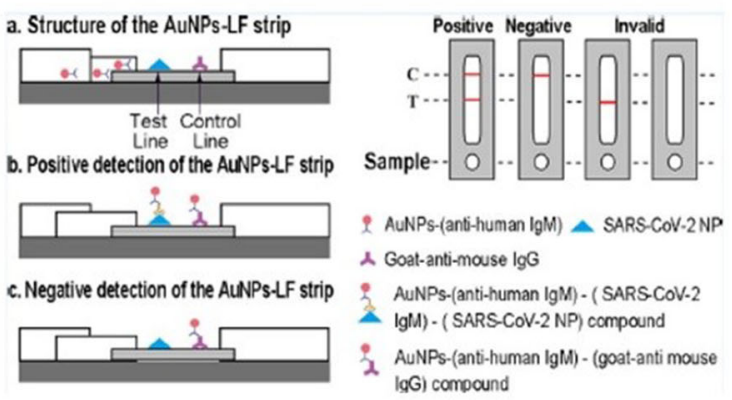

Fig. 2 Nanomaterial-based platform, a Selective colorimetric readout detection procedure of SARS-CoV-2 using AuNP. Reproduced from [110]. According to the journal: "This article is made available via the ACS COVID-19 subset for unrestricted RESEARCH re-use and analyses in any form or by any means with acknowledgement of the original source. These permissions are granted for the duration of the World Health Organization (WHO) declaration of COVID-19 as a global pandemic." b Explanation of AuNP-LF protocol in detection of a secreted antibodies in response of infection. Reproduced from [111], with permission from the American Chemical Society. c NW-FET platform; binding/
C

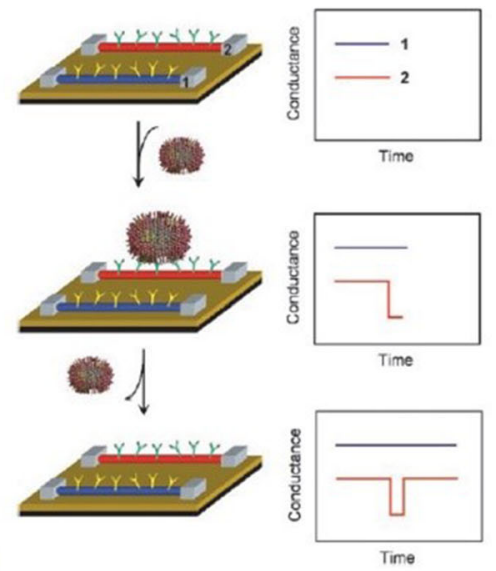

d
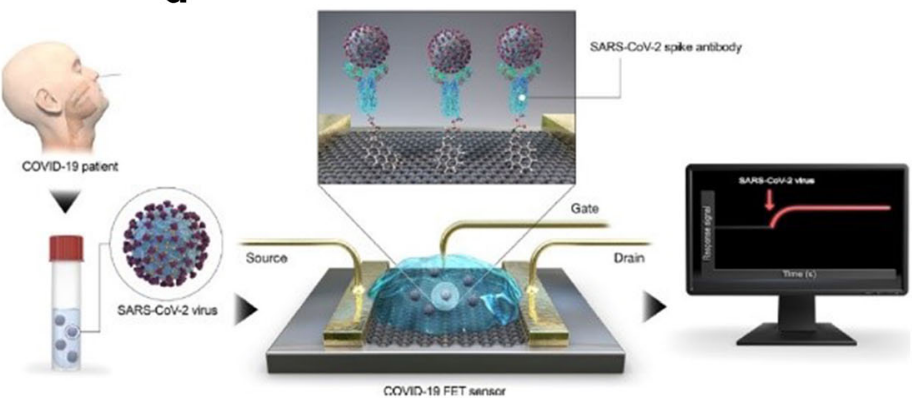

unbinding of an indicator to receptor coated NW leads to alter conductivity and rapid detection. Reproduced from [112], with permission from the National Academy of Sciences. d Field-effect transistor composed of coated graphene sheets which was introduced for the detection of SARSCoV-2. Reproduced from [113]. According to the journal: "This article is made available via the ACS COVID-19 subset for unrestricted RESEARCH re-use and analyses in any form or by any means with acknowledgement of the original source. These permissions are granted for the duration of the World Health Organization (WHO) declaration of COVID-19 as a global pandemic" use in this platform [131]. To prevent additional steps, Uhm et al. suggested that as POC biosensor, the detection of viral surface protein can be a more sensitive infection diagnostic tool. To achieve this purpose, they employed a functionalized SiNW-FET platform to detect hemagglutinin (HA) surface protein secreted by Swine flu (H1N1) virus [132].

Further, Malsagova et al. fabricated an aptamer-modified SiNW-FET for biospecific binding to the Hepatitis $\mathrm{C}$ protein marker (HCVcoreAg), leading to real-time detection of low marker concentrations $(0.3 \mathrm{pg} / \mathrm{mL})$ [133]. Also, Generalov et al. developed a rapid diagnosis tool (200-300 s) for the detection of Ebola virus VP40 protein, employing an SiNWFET platform for specific antigen/antibody interaction [134]. Graphene is a candidate for use in fabricating biosensors because of its electrical conductivity, high carrier mobility, and optical properties [135]. Seo et al. introduced a field-effect transistor composed of coated graphene sheets, which have immobilized antibodies against spike protein of SARS-CoV2. The proposed device (Fig. 2d) exhibited a highly sensitive platform for selective spike detection at concentrations of 100 $\mathrm{fg} / \mathrm{ml}[136]$. Instead of evaluating conductivity changes, NWbased platform can be utilized to detect specific molecules through the electrochemical impedance spectra (EIS). The development of DNA impedance-based label-free biosensors based on the use of tin-doped $\mathrm{WO}_{3} / \mathrm{In}_{2} \mathrm{O}_{3}$ [137] nanowires and ellurium-doped $\mathrm{ZnO}$ nanowires [138] for the detection of Hepatitis B virus has been reported. Interestingly, Chowdhury et al. proposed pulse-triggered ultrasensitive impedance-based biosensor composed of graphene quantum dots and gold-embedded polyaniline nanowires in which an external pulse was applied, during the hepatitis E virus accumulation phase, to increase expansion and sensitivity consequently [139]. This strategy can be adapted for FET-based diagnostic platform used for SARS-CoV-2.

On another frontier, microfluidic devices have been extensively investigated in recent years [140]. Based on the presence of the virus in the solution, it can be detected through virus receptor-coated device [141]. As mentioned earlier, 
ELISA technique could be applied for the detection of antibodies. To this end, the microfluidic platforms in combination of ELISA can lead to a rapid detection of the virus using small-volume samples [142]. In this relation, an immunoassay-based microfluidic device was used for the detection of Hendra virus IgG [143], influenza virus H5N1 [144], and avian influenza virus (AIV) [145]. Tripathi et al. reported the use of semi-automated on-chip ELISA for the detection of $\mathrm{IgG} / \mathrm{IgM}$ antibodies against SARS-CoV-2 [146]. In another study, Xia et al. developed a label-free MD-coated SiNW for the detection of H5N2 avian influenza viruses [147]. It is expected that more progress will be made on this issue in the future.

In addition, biomaterial-based surface biosensors such as quantum dot (QD)-mediated biosensing or gold nanoparticlesmediated biosensing have been shown to detect specific DNA sequences [148, 149]. These methods can be utilized to design biomaterials-based RNA detection. In this regard, RNAtoehold detection strategies in combination with ribosome or isothermal amplification have been utilized for the detection of viral RNA, based on enzymatic reporter and RNA converted to cDNA [150]. From the COVID-19 perspective, viralbiosensors such as CRISPR-based biosensors may provide quick and on-site testing of clinical samples (Fig. 3a) [151]. Recently, CRISPR-chip was established in combination with a graphene-based field effect transistor (FET) allowing for fast amplification-independent detection of nucleic acids within 15 min [154]. In addition, Mahari et al. developed gold nanoparticles (AuNPs)-based fluorine-doped tin oxide (FTO) immunosensor for the detection of the COVID-19 spike antigen. The device displayed results within 10-30 s (Fig. 3b) [152]. Surface plasmon resonance (SPR)-based biosensor has also been used in antibody detection application. Djaileb et al. utilized SPR-based biosensor coated SARS-CoV-2 nucleocapsid's recombinant protein for testing anti-SARS-CoV2 antibodies. This biosensor is a human serum-based labelfree rapid testing of the SARS-CoV-2 for antibodies. It takes 15 min to show results (Fig. 3c) [153].

\subsection{Biomaterials for developing prophylaxis and treatment for COVID-19}

A few drugs have been reported to reduce the duration of stay of COVID-19 patients in the hospital and intensive care unit and provide a reduction in the need for intubation and ventilation. Depending on the stage of disease, various drugs can be administered. Usually, supportive therapy treatment is given to patients to sustain adequate caloric intake, water, and electrolyte balance. The treatment methods such as immuno-, oxygen, and antiviral therapy, and organ support prevent and control cytokine storms, acute respiratory distress syndrome, organ failure, and secondary hospital infections [155-157].

\subsubsection{Theraputics}

The most widely used drugs for the treatment of COVID19 patients comprise antiviral drugs [158, 159], antiinflammatory drugs [160], and monoclonal antibodies [161]. The antiviral drugs' mechanism of action range from targeting viral proteins to cellular proteins and increasing the immune response to the viral infection [157]. Some of the clinically used drugs are Ribavirin [162], Lopinavir/Ritonavir [163], Remdesivir [164], Darunavir [165], Favipiravir [166], Sofosbuvir [167], Dexamethasone [168], and Chloroquine [164]. These drugs are commercially available in the form of tablets, capsules, oral suspensions, eye drops, topical creams, intravenous injections, or nasal ointment [169].

Unfortunately, most antiviral drugs are not suitable for oral or intravenous administration due to their low bioavailability and limited circulation time. Further, short half-life of antibodies, cytokines, and other protein-based drugs usually hinder their delivery to target sites [170]. Biomaterials offer various possibilities to solve the shortcomings of current therapeutic platforms. For example, advances in biomaterials for drug delivery will enable the development of new approaches $[169,171]$. Different biomaterials are used as drug carriers in viral diseases in the form of micro- or nanoparticles, or capsules [172-175]. Biomaterial-based drug delivery systems can also be useful to address the challenges related to the of administration of recently-developed therapeutics [176].

Using drug carriers capable of targeting the lung is very promising. In addition, because of the high surface area of the alveoli, systemically acting drugs can readily be delivered by inhalation[177]. Also, pulmonary carriers that encapsulate drugs or vaccines can be functionalized with specific antibodies to target certain cell types. Thus, the risk of drug side effects can be reduced. There are some examples of biomaterials-based drug delivery systems in the literature that were applied in the treatment of several disorders such as lung cancer and influenza [178-180]. Drugencapsulating natural biodegradable polymers, including cyclodextrin, albumin, alginate, chitosan, gelatin, collagen, and synthetic polymers including polylactide (PLA), polyglycolide (PLGA), polyacrylates, and polyanhydrides are suitable for the development of pulmonary therapeutic molecule delivery systems $[181,182]$.

\subsubsection{Vaccines}

There is an intensive research to develop vaccines for the prevention and management of COVID-19 [183]. To achieve this, it is essential to understand the pathogenesis of COVID19 and the effect of SARS-CoV-2 virus on infected patients [184].

Materials science and engineering mainly in the field of nanotechnology have suggested different strategies to inhibit 


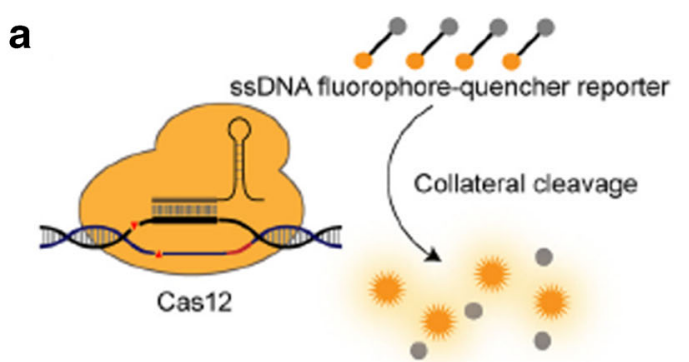

b

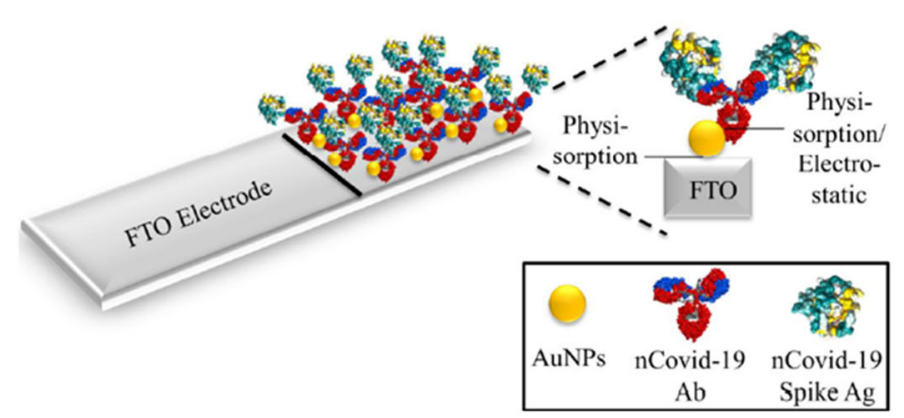

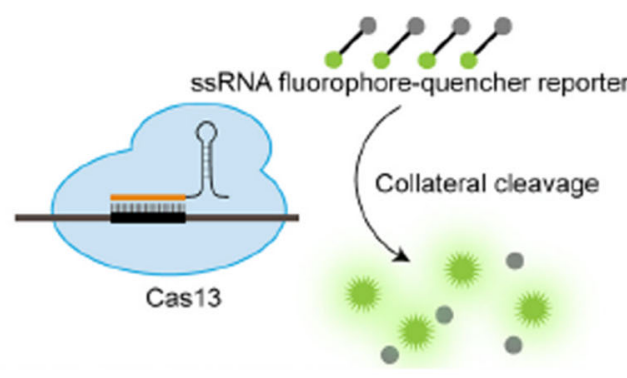

C

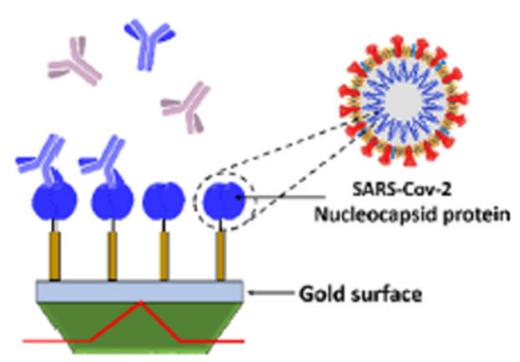

SPR based Biosensor
Fig. 3 Biosensors for the detection of SARS-CoV-2. a CRISPR-RNA based platform. Targets are detected by RNA-bound Cas protein, via complementary sequence. When the tertiary complex of Cas-crRNARNA was formed, fluorescent signal switches on. Reproduced from [151], with permission from Elsevier. b Gold nanoparticle (AuNPs)based fluorine-doped tin oxide (FTO) immunosensor. FTO electrode

viral surface receptors by using nanoparticles. For instance, Langellotto et al. fabricated a biomaterial vaccine which was based on the use of mesoporous silica rods (MSRs). After the effects of the prepared MSR vaccine were evaluated in vivo, it was shown that it can lead to strong protection against SARSCoV-2 [185]. Another example, is the use of lipid nanoparticle (LNP)-encapsulated mRNA vaccine [186].

Different methods have been used in vaccine studies thus far. The time taken for the preparation, preclinical tests, and clinical applications of vaccines have been improved with employing technological advances [187]. While conventional approaches use live attenuated viruses or vaccines conjugated with proteins, today recombinant proteins and viral vectors come to use [188]. Dai et al. presented a design containing $\mathrm{CoV}$ spike receptor-binding domain (RBD) for use in different beta-coronavirus vaccines, especially COVID19. Here, the RBD dimer design was prepared using MERS$\mathrm{CoV}$. Studies on mice with the prepared MERS-CoV (RBD) showed a protective effect against infection. Also, a significant increase in neutralizing antibody (NAb) titers was observed [189]. In the future, the immunopathogenic nature of COVID-19 should be investigated in detail, especially by developing characterization studies to assist in the development of COVID-19 vaccines. The development of different vaccines should continue with both preclinical and clinical studies [190]. Indicatively, two companies, CPfizer and CModerna, currently have been able to develop an mRNA-based vaccine composed of AuNPs conjugated with COVID-19 antibodies. Reproduced from [152], with permission from Author (S Gandhi). c Surface plasmon resonance (SPR)-based biosensor for the detection of the nucleo-capsid protein of SARS-CoV-2. Adapted from [153], with permission form the Author (Jean-Francois Masson)

that encodes critical parts of the protein related to SARS-CoV-2, allowing the stimulation of immune system [191, 192].

It should be noted that employing a vaccine adjuvant as a non-specific immune promoter can elevate immunogenicity and lead to a better response to the antigen used. For further details, readers are referred to a recently published review of various biomaterial-based adjuvant options which have been developed for the control of SARS pandemic [193].

\subsection{Biomaterials for targeting consequences of viral infection}

Antithrombotic materials SARS-CoV-2 infection can cause acute respiratory distress syndrome (ARDS) and several extrapulmonary indication that result from direct and indirect effects of viral infection such as cardiovascular, hematologic, and thrombotic sequelae $[194,195]$. ARDS is related to inflammatory dysfunction and coagulation; thereby it increases the risk of venous thromboembolism (VTE), thrombocytopenia, and bleeding [196]. Moreover, thrombosis has been implicated in patients who died of COVID-19, mainly due in part to widespread endothelial activation [197].

Although, limited data is available pertinent to thrombotic effects in COVID-19-infected patients, the prevalence of venous thromboembolism may be estimated between 25 and $30 \%$ in critically infected patients who were under mechanical ventilation [198, 199]. Current data on antithrombotic therapy 
to improve the result obtained from patients with COVID-19 as well as administering agents with an optimum dose and agent for thromboprophylaxis is still confined. It is noteworthy that targeted drug delivery strategy to the local sites of damaged vascular endothelium may enhance the local effect. Microbubble carrier delivery coated with dextrose and albumin enable binding to sites of vascular injury with no additional effect on vessel injury [200]. The anticoagulant heparin can be administered directly to the lung by inhalation in cases of COVID-19 [201].

Recently, bioinert synthetic polymers such as poly(2methoxyethyl acrylate) (PMEA) with antithrombotic properties have been developed. PMEA is a water-insoluble polymer, thereby PMEA can be applied as a blood compatible surface to be used on various materials for the treatment of patients with heparin-associated disorders [202]. In addition, PMEA coating has been utilized in extracorporeal membrane oxygenation (ECMO) devices, which are used for the treatment of acute respiratory failure [203], and SARS-CoV-2 (the COVID-19) [204]. Unfortunately, its use as a coating biomaterial led to only temporary antithrombotic effect [202]. Therefore, Nishimura et al. developed a novel hybrid polymer silsesquioxane (SQ) and PMEA hybrid to enhance the stability of coated PMEA polymer (Fig. 4) [202]. The hybrid coating polymer exhibited excellent antithrombotic properties [202].

\subsection{Antiviral therapy and biomaterials for drug delivery}

The critical role of biomaterials for the development of various treatment methods of COVID-19 involves antiviral drug delivery and immunization systems. Various therapeutic strategies have been adopted from the viral lifecycle steps. An example of direct modality to neutralize SARS-CoV-2 is blocking the angiotensin-converting enzyme 2 (ACE2) receptors that virus uses to enter cells, e.g., lung, intestine, or kidney [205]. Recently, different antiviral components have been investigated for their efficiency. Among these, antiviral drugs, e.g., Lopinavir, Ritonavir, exhibited an inhibitory effect on the action of proteases in human infected cells [206]. After the virus enters the host cells, it has to replicate and produce many copies of itself. It was obvious from previous studies on SARS-CoV virus that some nonstructural proteins (Nsp) such as Nsp1-11 and Nsp1-16 have a central role in virus replication. These proteins are linked to the replication of the viral RNA. Therefore, Nsp proteins can be proposed as another possible target to stop the replication of SARS-CoV-2 virus [207].

Cytokinesis may occur due to the activation of various pathways and it can lead to a cytokine storm [208]. Hence, the prevention of the cytokine storm has been proposed as another therapeutic goal to combat the effects of SARS-
CoV-2 by using IL-1 blocker. In this context, promising drugs including anakinra, tocilizumab, steroids, and immunoglobulins have been proposed to regulate the immune response. The application of nucleoside analogues, such as Remdesivir, which targets the RNA-dependent polymerase, caused the suppression of the synthesis of viral RNA. As a result, the use of drugs that interact with the viral genetic material, directly or indirectly, can be used to lower the production of pro-inflammatory cytokines. Currently, this strategy is under clinical study [209].

A further target of SARS-CoV-2 therapy is the c-Jun N-terminal kinase (JNK) pathway, which enhances the production of pro-inflammatory factors that result in lung damage. Thus, the application of specific biomaterials and drug delivery systems addressing different stages of the viral lifecycle can be used as specific therapeutics for the treatment of COVID-19 patients. Unfortunately, these drugs have side effects. For example, Lopinavir and Ritonavir may lead to vomiting, nausea, and hepatic damage [210]. Therefore, their use was limited to only severe cases.

Biomaterial-based delivery combined with nano-systems can be used to increase the local delivery of drugs while reducing the chance of undesired side effects. Moreover, biomaterial-based delivery systems might extend the half-life and decrease the immunogenicity of drugs [211,212].

In fact, the development of an appropriate delivery system is necessary for achieving better outcomes. Controlled release formulation of drugs could minimize the risk of adverse side effects through a drug release at the target site [213]. Targeted delivery of drugs can lead to additional improvement of efficiency and reduced toxicity [1]. Although different drug delivery systems have been suggested, polymer-conjugated drugs provide a new prospective delivery system for COVID-19 therapeutics. The reason is that polymer drug delivery systems can provide protection against enzymatic degradation [214]. Another possible strategy would be the use of mucoadhesive drug delivery systems that can increase the presence of long-lasting drugs in the mucus layer, and this should be taken into consideration. For example, a cationic polymer such as chitosan has been used as mucoadhesive polymer due to the formation of electrostatic bonds with sialic acid residues on the glycoproteins in the mucosal fluid [215].

To take targeted delivery into consideration, the design of the delivery system should be in accordance with the natural route of virus entry and infection. For example, SARS virus is transmitted through the respiratory system, thus mucosal dendritic cells (DCs) in the respiratory tract might be an ideal target for the uptake of targeted nanoparticles. DSs represent antigen-presenting cells (APCs), which have effective role in the development of the response of the immune system [216]. Obviously, the choice of biomaterials in the delivery system is of paramount importance. Chitosan as a cationic 


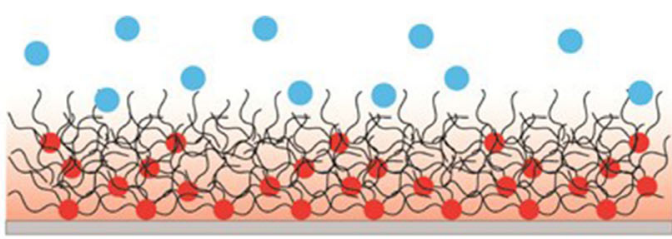

Hydration-induced Segregation of PMEA moiety

—: PMEA moiety $\odot$ : SQ moiety $\bigcirc$ : water

\section{Endothelial Cell \\ Adhesive Property}

Human Umbilical Vein Endothelial Cells (HUVECs)

\section{Antithrombotic Property}

\section{Silsesquioxane(SQ)/Poly(2-methoxyethyl acrylate)(PMEA) Hybrid}

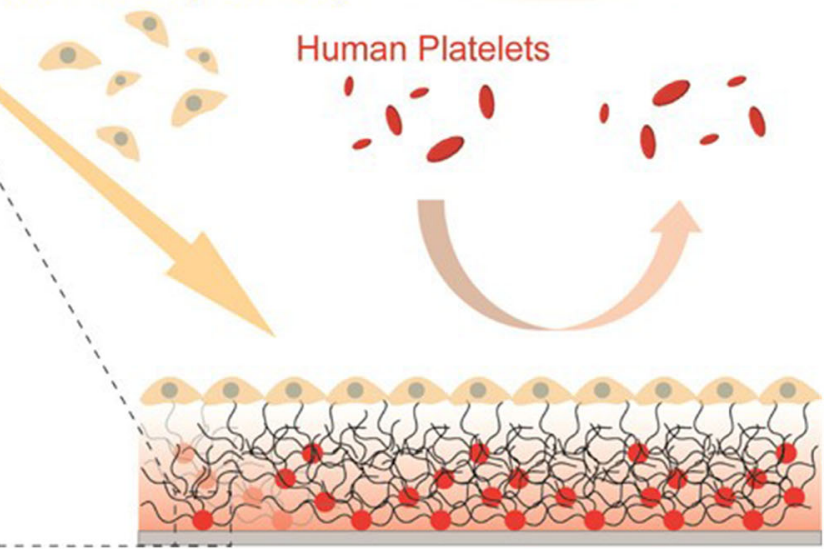

Fig. 4 Schematic illustration representing the synthesis of the SQ/PMEA hybrids. Reproduced from [202], with permission from the American Chemical Society

polymer supplies appropriate binding affinity with nucleic acids, thus chitosan and its derivatives can be used as excellent nucleic acid delivery vehicles through nasal route [217]. In a study conducted by Raghuwanshi et al., functionalized chitosan nanoparticles with bifunctional fusion protein (bfFp) vector were used to increase the selective targeting of respiratory DCs. Plasmid-encoding N protein of SARS (pVAXN) was used as a selective antigen for the DNA delivery using chitosan. The outcome of the study showed better boosting of both mucosal and systemic immune responses, as compared to the intranasal delivery of naked plasmid DNA [216].

Recently, smart materials have been introduced as biologically responsive materials for different purposes [218, 219] including the sensor-based detection of analytes [220], to interface with synthetic DNA constructs [221]. For example, English et al. developed a CRISPR-mediated hydrogel by utilizing the enzymatic properties of Cas12a, which only relied on the sgRNA molecule to diagnose fragment of mecA antibiotic-resistance gene of methicillin-resistant Staphylococcus aureus (MRSA). Having selected MRSA, the hydrogel responds to a defined sequence of DNA. They reported various applications of CRISPR-responsive hydrogels such as tissue engineering and bioelectronic interfaces for diagnostic applications. The latter was designed as a microfluidic paper-based analytical device ( $\mu$ PADs) with electronic monitoring systems through hydrogel actuation with CRISPR/Cas technology reaction. The system was implemented by triggering the cleavage of the DNA linker by the Cas12a in the presence of targets, thus preventing the cross-linking of polyacrylamide hydrogel in the channel, enabling buffer flow in the channel. Moreover, the CRISPR- $\mu$ PAD device was equipped with an isothermal application step to use the reverse transcription (for the detection of genomic RNA). In this context, Ebola genomic RNA was detected by buffer flow through the device in samples incubated with Cas12a (Fig. 5) [222].

Furthermore, the introduction of biomaterials as innovative targeting agents provide a safe way for the delivery of therapeutic molecules. A recent therapeutic strategy that has been suggested for use in COVID-19 patients is the monitoring of NETosis . Elevated levels of NETosis markers such as cfDNA have been found in critically infected patients, thus represent a possible therapeutic target for the treatment of virus-induced sepsis [223]. In this regard, Lee et al. fabricated a long-acting nanoparticulate DNase-1 by coating of PLGA nanoparticles with polydopamine (PD). The bio-adhesive PLGA-PD NPs were then coated with poly(ethylene glycol) and recombinant DNase-1 to prepare DNase-1-coated polydopamine-poly(ethylene glycol) nanoparticulates. Following intravenous administration of these NPs, they have confirmed an effective suppression of NETosis factors such as cell-free DNA (cfDNA) in blood samples of COVID19 patients (Fig. 6). The results of this study revealed an improved survival in sepsis mouse model because of inhibited NETosis factors [224].

It can be seen that biomaterials derived from designed peptide and protein sequences have captured much attention over the last two decades. Recently, coiled-coil hydrogels were generated from the most studied protein motifs. In one study, coiled-coil nanoparticles with antiviral properties against SARS were fabricated [225]. 


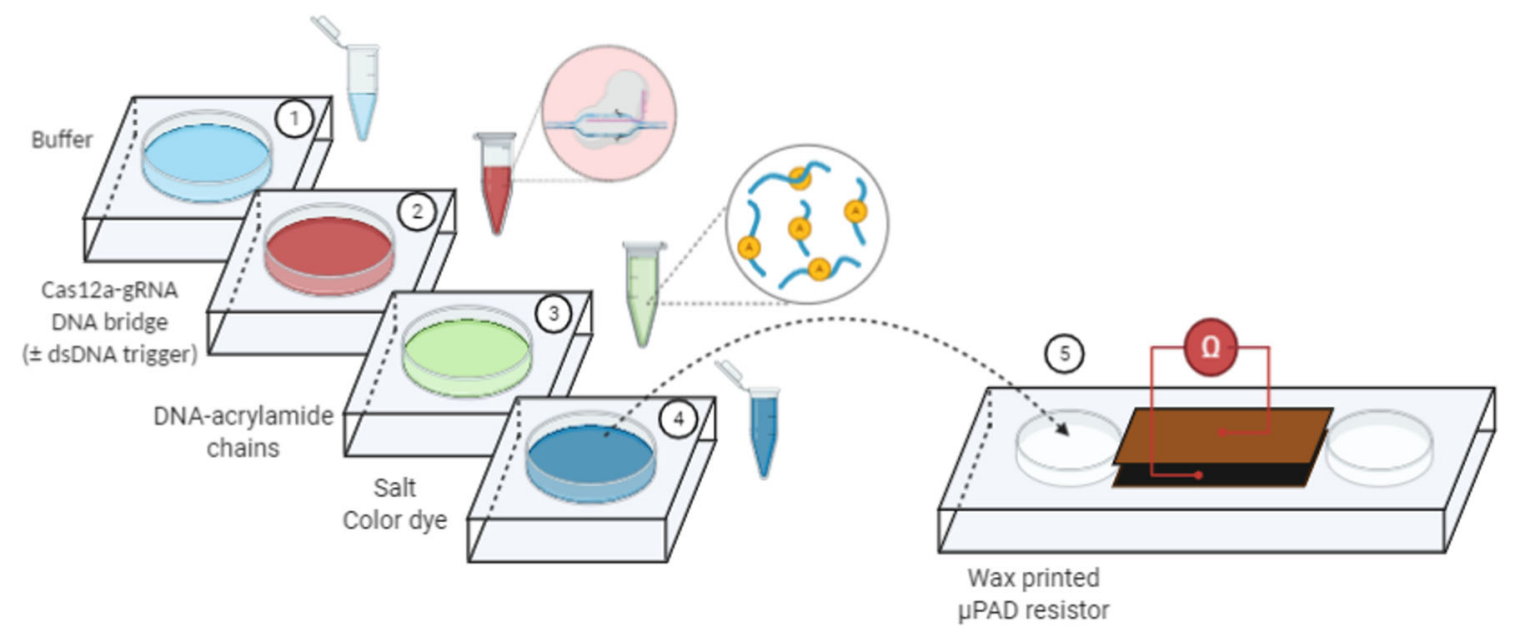

Fig. 5 Schematic illustration showing the $\mu \mathrm{PAD}$ design combined with CRISPR gel and electrical readout. Layers 1 to 4 form a continuous channel on folding terminate into in a lateral flow channel in layer 5 .
The channel in layer 5 was covered with conductive tape to read buffer flow as an electric signal, adapted from [222]

\section{Advantages and limitations of biomaterials applied for COVID-19 diagnosis and therapy}

Following the emergence of the COVID-19 pandemic, several laboratory-based diagnostic techniques were introduced. Longer times and the need for equipped devices are the limitations of this diagnostic methods. To overcome this, it is critical to have a powerful POC biomaterial-based platform capable of rapid and accurate diagnosis using throat swabs or blood samples. It will be interesting to provide self-testing kits like the home pregnancy test. Very recently, such kits have been introduced [226, 227]. This makes it possible to become aware of the infection quickly and quarantine. Additionally, the COVID-19 crisis has led to limitations to travelling. Thus, developing a POC platform with accurate detection of SARSCoV-2 at the airports will allow people to return to normal conditions. To date, biomedical researchers tried to use engineering approaches for the processing of a biological cascade, resulting in virus detection. To this end, Joung et al. commercialized the POC platform based on SHERLOCK strategy, which made it possible to detect SARS-CoV-2 using lateral flow strips [227]. Further, Shan et al. introduced a multiplexed biosensor with high accuracy for the diagnosis of SARS-CoV2 infection by detecting specific volatile organic compounds in exhaled air [226]. In an interesting pilot study, TorrenteRodriguez et al. designed wireless multiplexed laser-engraved graphene immunosensors (COVID Rapidplex) by which the level of specific biomarkers such as $\operatorname{IgG}$ and $\operatorname{IgM}$, SARS-CoV-2 antigens, as well as C-reactive protein (CRP) in serum and saliva samples can electrochemically be quantified. Authors also suggested that this platform can be considered as ultrasensitive, rapid, and selective homebased diagnosis test [228]. Jiao et al. presented DNA nanoscaffold which is made by the self-assembly of long DNA strands and self-quenching probes (H1) as a sensing element for the detection of RNA corresponding to SARSCoV-2 within 10 min at $15-35^{\circ} \mathrm{C}$ [229]. Despite recent progress in the development of biomaterial-based diagnostic platforms, most of them are not yet in wide clinical use.
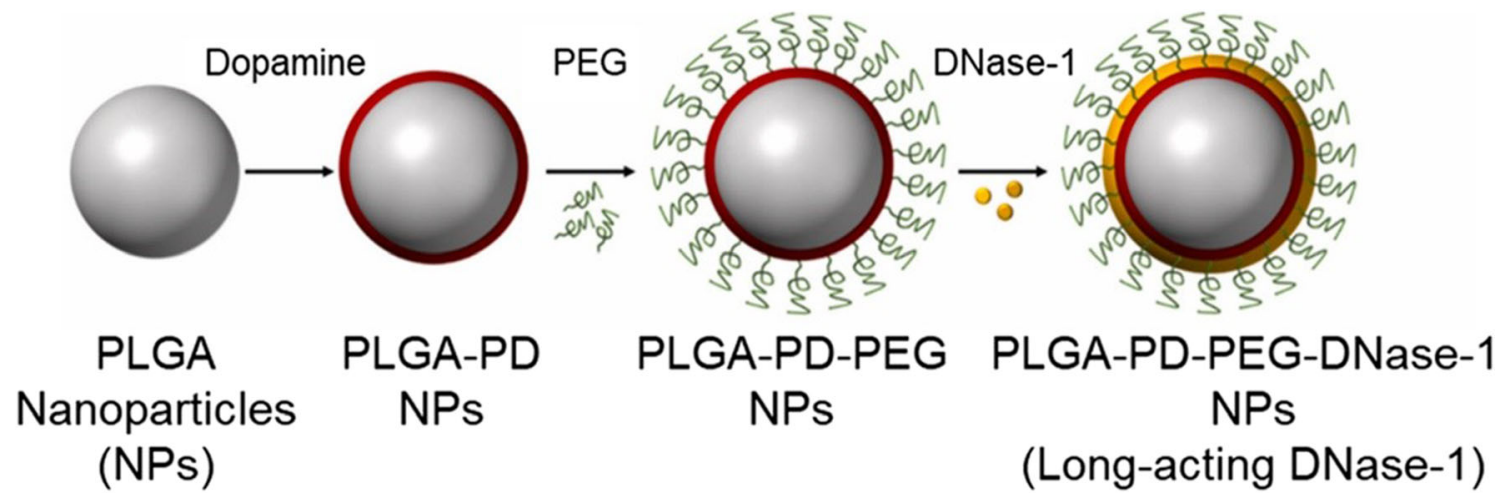

Fig. 6. Fabrication of DNase-1-coated polydopamine-poly(ethylene glycol) nanoparticles. The surface of the PLGA nanoparticles was coated with polydopamine to immobilize DNase-1. Reproduced from [224], with permission from Elsevier 
Following COVID-19 crisis, researchers have been exploring the the virus in terms of genome sequencing and surface proteins, making it possible to figure out the development of broad-spectrum effective therapeutic agents . To date, some (i) antiviral drugs such as Ribavirin, Remdesivir, and Chloroquine; (ii) immunomodulatory agents; and (iii) viral protease inhibitors have been tested on infected patients, and some of them had positive results. However, it is not possible to use some specific treatments such as antiinflammatory cytokines and antibodies (for blocking specific ligands) based on conventional administration routes such as oral or intravenous ways, due to their short half-life [1]. Many of the introduced small molecules have short circulation time due to high hydrophobicity and low stability. Further, a positive effect on SARS-CoV-2 infection by some agents has been reported, but their clinical application has failed due to adverse off-target effects [230, 231]. With this in mind, the design of biomaterial-based targeted drug delivery systems combined with sustained hydrophobic drug delivery and codelivery of effective agents that consider virus receptors can be an interesting approach [6, 232]. For instance, the use of Azithromycin and antiviral drugs was proved effective, and it was reported that its release from PLGA nanoparticles can be sustained over 60 days [233]. However, sequential mutations that occur in the virus limit the use of specific targeting agents [232]. Nevertheless, an intelligent delivery system should be designed for viruses with the fewest mutations.

Further, designing drug systems and even vaccines for preclinical tests requires the use of laboratory models that can mimic human physiology to reduce clinical trials' error rate. Because animal models cannot fully recapitulate human physiology, in vitro microphysiological models such as organoids and organ- and lab-on-a-chip systems have been developed, with the ability to scale up and allow for a more accurate evaluation of drugs and vaccines $[6,18]$. To date, human organoid platforms including those of the small intestine [234, 235], gut [236], kidney [79], and lung [25] for investigating SARS-CoV-2 were developed. For creating a reliable and biomimetic in vitro model, the multicellularity of organs such as the lung is a daunting challenge. For more details, readers are referred to a comprehensive review by Miller et al. [61]. The development of a reliable in vitro lung model for SARS-CoV-2 studies allows the (i) use of specific human instead of animal cells, (ii) co-culture of variety types of pulmonary cells, and (iii) mimicking pulmonary architecture. To achieve success, all of these approaches require close cooperation of medical scientists and biomedical engineers [18].

To date, some biodegradable biomaterials have been used for the development of various preparations such as PLGA nanoparticles [237] [238], mesoporous silica rods [239], and chitosan [240] were employed as vaccine platforms, which can be extended to SARS-CoV-2 vaccine development. Of note, the size, shape, and other physicochemical features of the proposed platform should be carefully designed to achieve required effects on the immune system. However, most of the introduced preparations are still in the preclinical testing phase and have not reached clinical application yet [18].

\section{Current challenges and future}

After the COVID-19 outbreak, engineers in the field of biomaterials have been actively working to develop new methods for diagnosis and treatment of the disease. For instance, researchers developed 3D-printed nasal swabs for sample collection. However, there are still challenges facing some nanoparticle-based preparations in terms of biocompatibility. Perhaps the most crucial challenge is the high mutation rate in the virus, which causes diagnostic, therapeutic, and vaccine targets to fail to function correctly [108]. For example, since $\mathrm{RBD}$ is a variable sequence in the $\mathrm{CoV}$ genome, the use of RBD-based vaccines may not be satisfactory [241]. Also, the scale-up of the biomaterials-based structures requires extensive research and studies to minimize the risk of side effects [108]. On the other hand, multidisciplinary approach is required for the design of robust biological systems and to fabricate novel therapeutics and devices.

Another major challenge, which is related to SARS-CoV-2 virus is its different behavior in different hosts. This requires the design of highly biomimetic organoids and organ-on-achip systems in which behavioral variability can be assessed [108]. In vitro models should mimic the dynamic interactions between the virus and the host tissue/organ components. Lately, researchers have been able to design mini-organoids (called alveolospheres) that can be used to examine how alveolar cells respond to SARS-CoV-2 infection. However, there remains the challenges related to the development of robust organoid models. Also, there are big gaps between the current organoid models and how organs function in the body. To bridge these gaps, researchers have been exploring the combination of organoids and organ-on-a-chip devices to better mimic native organ structure and function [242].

Depending on the stage of infection with SARS-CoV-2 virus, certain drug delivery systems need to be used. Because of viral illness, several extrapulmonary problems are manifested, thus successful application of biomaterialbased drug delivery strategies is dependent on profound understanding the pathophysiology of COVID-19. This would also enhance the effectiveness of therapy and reduce the risk of side effects. The initial targeting of receptors such as ACE-2 and TMPRSS2 that the virus utilizes to enter the cells is a paramount issue, thereby it could disrupt SARSCoV-2 and its interaction with receptors [196]. In addition, the interaction between the $\mathrm{S}$ protein and heparin sulfate chains of proteoglycans found in human lung tissue 
presents a potential target for tackling by using an antithrombotic agent such as heparin. It is also thought that combination delivery system might mitigate acute symptoms in patients.

Collectively, it can be concluded that various aspects are involved in advancing the utilization of biomaterials as a practical option for diagnosing, vaccinating against and treating SARS-CoV-2 infection. To improve our knowledge of COVID-19, predict virus behavior, develop effective medications and vaccines, the integration of different disciplines is required. It is anticipated that we will see increasingly more biomaterial-based products for the diagnosis, treatment, and vaccination of COVID-19. The good news at the time of writing this review is that the two vaccines developed by Pfizer and Moderna were very effective for the vaccination against SARS-CoV-2, which is a big step in the fight against this pandemic.

\section{Conclusions}

Biomaterials represent an important and advancing area of science that can contribute to our capabilities of prevention and treatment of serious infectious diseases such as COVID19. Biomaterials science has been already mobilized in this direction and successful examples include the development of nucleic acid (RNA/DNA) and protein (antigen/antibody) biosensors, vaccine delivery, antiviral delivery, and organoids used for the study of SARS-CoV-2 infection, its sequelae and complications. There are still many areas that can potentially benefit to a large extent from the surge of new and smart materials such as CRISPR-based biosensors, FET-based transistors, protein-based vaccines, metallic and self-assembled nanovaccines, and organoid technology. In the case of diagnostic platforms, the development of a very high-precision lab-independent POC biosensors is required. However, while much progress has been made in the use of biomaterials for the development of diagnostic biosensors and vaccines, there is still a need for more extensive studies to develop therapeutics for the treatment of COVID-19. Since viruses have weak therapeutic targets and they have successive mutations, it is challenging to develop targeted antiviral delivery systems. Therefore, the development of a smart antiviral system based on biomaterials will make significant impact. It is predicted that the development of organ-on-a-chip systems will be very useful for the study of COVID-19 infection and drug testing in the future. Nevertheless, the cooperation of different disciplines is required to develop novel biomaterialbased strategies for the prevention, treatment and monitoring of COVID-19.
Acknowledgements The authors acknowledge funding from the American Heart Association (442611-NU-80922). Y. N. Ertas acknowledges funding support from 2232 International Fellowship for Outstanding Researchers Program of TÜBİTAK (Project No: 118C346). Thanks are due to Fatemeh Rastegar-Adib for helping with drawing parts of Fig. 1 and Fig. 5.

\section{Declarations}

Competing interests The authors declare no competing interests.

\section{References}

1. D. Chakhalian, R.B. Shultz, C.E. Miles, J. Kohn, Opportunities for biomaterials to address the challenges of COVID-19. J. Biomed. Mater. Res. A 108(10), 1974-1990 (2020)

2. W.J. Wiersinga, A. Rhodes, A.C. Cheng, S.J. Peacock, H.C. Prescott, Pathophysiology, transmission, diagnosis, and treatment of coronavirus disease 2019 (COVID-19): a review. Jama 324(8), 782-793 (2020)

3. S.K. Vashist, In vitro diagnostic assays for COVID-19: recent advances and emerging trends (Multidisciplinary Digital Publishing Institute, 2020)

4. J.S. Tregoning, E.S. Brown, H.M. Cheeseman, K.E. Flight, S.L. Higham, N.M. Lemm, B.F. Pierce, D.C. Stirling, Z. Wang, K.M. Pollock, Vaccines for COVID-19. Clin. Exp. Immunol. 202(2), 162-192 (2020)

5. H.T. Sun, AM, B.Q. Luu, J. Widdicombe, N. Ashammakhi, S. Li, Recent advances in in vitro lung microphysiological systems for Covid-19 modeling and drug development. Curr. Med. Chem. (2020)

6. Z. Tang, N. Kong, X. Zhang, Y. Liu, P. Hu, S. Mou, P. Liljeström, J. Shi, W. Tan, J.S. Kim, Y. Cao, R. Langer, K.W. Leong, O.C. Farokhzad, W. Tao, A materials-science perspective on tackling COVID-19. Nat. Rev. Mater. (2020)

7. S. Talebian, G.G. Wallace, A. Schroeder, F. Stellacci, J. Conde, Nanotechnology-based disinfectants and sensors for SARS-CoV2. Nat. Nanotechnol. 15(8), 618-621 (2020)

8. Y. Yu, F. Bu, H. Zhou, Y. Wang, J. Cui, X. Wang, G. Nie, H.H. Xiao, Biosafety Materials: An Emerging New Research Direction of Materials Science from COVID-19 Outbreak. Mater. Chem. Front. (2020)

9. H.S. Maghdid, K.Z. Ghafoor, A.S. Sadiq, K. Curran, K. Rabie, A novel ai-enabled framework to diagnose coronavirus covid 19 using smartphone embedded sensors: design study. arXiv preprint arXiv 2003, 07434 (2020)

10. S. Feng, C. Shen, N. Xia, W. Song, M. Fan, B.J. Cowling, Rational use of face masks in the COVID-19 pandemic. Lancet Respir. Med. 8(5), 434-436 (2020)

11. E. Mahase, Covid-19: UK could delay non-urgent care and call doctors back from leave and retirement. British Medical Journal Publishing Group (2020)

12. E. Livingston, A. Desai, M. Berkwits, Sourcing personal protective equipment during the COVID-19 pandemic. Jama 323(19), 1912-1914 (2020)

13. M.A. Matthay, J.M. Aldrich, J.E. Gotts, Treatment for severe acute respiratory distress syndrome from COVID-19. Lancet Respir. Med. 8(5), 433-434 (2020)

14. N.A. Peppas, J.Z. Hilt, A. Khademhosseini, R. Langer, Hydrogels in biology and medicine: from molecular principles to bionanotechnology. Adv. Mater. 18(11), 1345-1360 (2006) 
15. A. Singh, M. Kumar, A.K. Dubey, Effect of pre-existing diseases on COVID-19 infection and role of new sensors and biomaterials for its detection and treatment. Medical Devices \& Sensors, e10140

16. P. Cao, J. Shi, J. Zhang, X. Wang, J.T. Jung, Z. Wang, Z. Cui, Y.M. Lee, Piezoelectric PVDF membranes for use in anaerobic membrane bioreactor (AnMBR) and their antifouling performance. J. Membr. Sci. 118037 (2020)

17. R. Langer, J.P. Vacanti, Tissue engineering. Science 260(5110), 920-926 (1993)

18. A.M. Tatara, Role of tissue engineering in COVID-19 and future viral outbreaks. Tissue Eng. A 26(9-10), 468-474 (2020)

19. P. Harikrishnan, A. Krishnan, Tissue engineering strategies in Covid-19 research, Trends in Biomaterials \& Artificial Organs 34 (2020).

20. A. Shafiee, L. Moradi, M. Lim, J. Brown, Coronavirus disease 2019: a tissue engineering and regenerative medicine perspective. Stem Cells Transl. Med. (2020)

21. E. Davoodi, E. Sarikhani, H. Montazerian, S. Ahadian, M. Costantini, W. Swieszkowski, S.M. Willerth, K. Walus, M. Mofidfar, E. Toyserkani, A. Khademhosseini, N. Ashammakhi, Extrusion and microfluidic-based bioprinting to fabricate biomimetic tissues and organs. Adv. Mater. Technol. 5(8), 1901044 (2020)

22. R. Seyedmahmoud, B. Çelebi-Saltik, N. Barros, R. Nasiri, E. Banton, A. Shamloo, N. Ashammakhi, M.R. Dokmeci, S. Ahadian, Three-dimensional bioprinting of functional skeletal muscle tissue using gelatinmethacryloyl-alginate bioinks, micromachines (Basel) 10(10) (2019).

23. N. Ashammakhi, S. Ahadian, I. Pountos, S.K. Hu, N. Tellisi, P. Bandaru, S. Ostrovidov, M.R. Dokmeci, A. Khademhosseini, In situ three-dimensional printing for reparative and regenerative therapy. Biomed. Microdevices 21(2), 42 (2019)

24. N. Ashammakhi, O. Kaarela, P. Ferretti, Pulling and pushing stem cells to control their differentiation. Journal of Craniofacial Surgery 29(3), 804-806 (2018)

25. C. Tindle, M. Fuller, A. Fonseca, S. Taheri, S.-R. Ibeawuchi, N. Beutler, A. Claire, V. Castillo, M. Hernandez, H. Russo, Adult stem cell-derived complete lung organoid models emulate lung disease in COVID-19, bioRxiv (2020).

26. N. Ashammakhi, E. Elkhammas, A. Hasan, Translating advances in organ-on-a-chip technology for supporting organs. J Biomed Mater Res B Appl Biomater 107(6), 2006-2018 (2019)

27. N.A. Ashammakhi, A. Elzagheid, organ-on-a-chip: new tool for personalized medicine. J Craniofac Surg 29(4), 823-824 (2018)

28. H. Tang, Y. Abouleila, L. Si, A.M. Ortega-Prieto, C.L. Mummery, D.E. Ingber, A. Mashaghi, human organs-on-chips for virology. Trends Microbiol. 28(11), 934-946 (2020)

29. A. Shpichka, P. Bikmulina, M. Peshkova, N. Kosheleva, I. Zurina, E. Zahmatkesh, N. Khoshdel-Rad, M. Lipina, E. Golubeva, D. Butnaru, Engineering a model to study viral infections: bioprinting, microfluidics, and organoids to defeat coronavirus disease 2019 (COVID-19). International Journal of Bioprinting 6(4) $(2020)$

30. G. Liu, B.T. David, M. Trawczynski, R.G. Fessler, Advances in pluripotent stem cells: history, mechanisms, technologies, and applications. Stem Cell Rev. Rep. 16(1), 3-32 (2020)

31. A.D. Ebert, C.N. Svendsen, Human stem cells and drug screening: opportunities and challenges. Nat. Rev. Drug Discov. 9(5), 367$372(2010)$

32. Z. Lin, Q. Gao, F. Qian, M. Jinlian, Z. Lishi, C. Tian, Q. Yu, C. Zhenhua, W. Ping, B. Lin, The nucleocapsid protein of SARSCoV-2 abolished pluripotency in human induced pluripotent stem cells, Available at SSRN 3561932 (2020).

33. W. Chrzanowski, S.Y. Kim, L. McClements, Can Stem Cells Beat COVID-19: Advancing stem cells and extracellular vesicles toward mainstream medicine for lung injuries associated with SARS-CoV-2 infections. Front. Bioeng. Biotechnol. 8, 554 (2020)

34. B. Bose, Induced Pluripotent Stem Cells (iPSCs) Derived 3D human lung organoids from different ethnicities to understand the SARS-CoV2 severity/infectivity percentage. Stem Cell Rev. Rep. 1 (2020)

35. Y.-W. Chen, S.X. Huang, A.L.R.T. De Carvalho, S.-H. Ho, M.N. Islam, S. Volpi, L.D. Notarangelo, M. Ciancanelli, J.-L. Casanova, J. Bhattacharya, A three-dimensional model of human lung development and disease from pluripotent stem cells. Nat. Cell Biol. 19(5), 542-549 (2017)

36. D.C. Wilkinson, J.A. Alva-Ornelas, J.M. Sucre, P. Vijayaraj, A. Durra, W. Richardson, S.J. Jonas, M.K. Paul, S. Karumbayaram, B. Dunn, Development of a three-dimensional bioengineering technology to generate lung tissue for personalized disease modeling. Stem Cells Transl. Med. 6(2), 622-633 (2017)

37. Z. Leng, R. Zhu, W. Hou, Y. Feng, Y. Yang, Q. Han, G. Shan, F. Meng, D. Du, S. Wang, Transplantation of ACE2-mesenchymal stem cells improves the outcome of patients with COVID-19 pneumonia. Aging Dis. 11(2), 216 (2020)

38. A. Nasef, N. Ashammakhi, L. Fouillard, Immunomodulatory effect of mesenchymal stromal cells: possible mechanisms. Regen. Med. 3(4), 531-546 (2008)

39. A.K. GÜREL, Immunomodulatory Effect of Mesenchymal Stem Cells in Respiratory Tract Infections Caused by Covid-19. MEDICAL SCIENCES AND BIOTECHNOLOGY BOOK 10 (2020)

40. P. Yadav, R. Vats, A. Bano, R. Bhardwaj, Mesenchymal stem cell immunomodulation and regeneration therapeutics as an ameliorative approach for COVID-19 pandemics. Life Sci. 118588 (2020)

41. F. Lin, T.E. Ichim, S. Pingle, L.D. Jones, S. Kesari, S. Ashili, Mesenchymal stem cells as living anti-inflammatory therapy for COVID-19 related acute respiratory distress syndrome. World journal of stem cells 12(10), 1067 (2020)

42. S. Chen, G. Cui, C. Peng, M.F. Lavin, X. Sun, E. Zhang, Y. Yang, Y. Guan, Z. Du, H. Shao, Transplantation of adipose-derived mesenchymal stem cells attenuates pulmonary fibrosis of silicosis via anti-inflammatory and anti-apoptosis effects in rats. Stem Cell Res Ther 9(1), 1-12 (2018)

43. K.R. Parekh, J. Nawroth, A. Pai, S.M. Busch, C.N. Senger, A.L. Ryan, Stem cells and lung regeneration. Am. J. Phys. Cell Phys. 319(4), C675-C693 (2020)

44. U.B. Savukinas, S.R. Enes, A.A. Sjöland, G. WestergrenThorsson, Concise review: the bystander effect: mesenchymal stem cell-mediated lung repair. Stem Cells 34(6), 1437-1444 (2016)

45. M. Gomez-Salazar, Z.N. Gonzalez-Galofre, J. Casamitjana, M. Crisan, A.W. James, B. Péault, Five decades later, are mesenchymal stem cells still relevant? Front. Bioeng. Biotechnol. 8, 148 (2020)

46. J.W. Lee, A. Krasnodembskaya, D.H. McKenna, Y. Song, J. Abbott, M.A. Matthay, Therapeutic effects of human mesenchymal stem cells in ex vivo human lungs injured with live bacteria. Am. J. Respir. Crit. Care Med. 187(7), 751-760 (2013)

47. M. Zayed, K. Iohara, Immunomodulation and regeneration properties of dental pulp stem cells: a potential therapy to treat coronavirus disease 2019. Cell Transplant. 29, 0963689720952089 (2020)

48. F. Ji, L. Li, Z. Li, Y. Jin, W. Liu, Mesenchymal stem cells as a potential treatment for critically ill patients with coronavirus disease 2019. Stem Cells Transl. Med. (2020)

49. J.K. Gardner, M.M. Herbst-Kralovetz, Three-dimensional rotating wall vessel-derived cell culture models for studying virus-host interactions. Viruses 8(11), 304 (2016) 
50. T.-Y. Ling, M.-D. Kuo, C.-L. Li, L.Y. Alice, Y.-H. Huang, T.-J. $\mathrm{Wu}$, Y.-C. Lin, S.-H. Chen, J. Yu, Identification of pulmonary Oct-4+ stem/progenitor cells and demonstration of their susceptibility to SARS coronavirus (SARS-CoV) infection in vitro. Proc. Natl. Acad. Sci. 103(25), 9530-9535 (2006)

51. B. Yu, X. Zhang, X. Li, Exosomes derived from mesenchymal stem cells. Int. J. Mol. Sci. 15(3), 4142-4157 (2014)

52. G. Van Niel, G. d'Angelo, G. Raposo, Shedding light on the cell biology of extracellular vesicles. Nat. Rev. Mol. Cell Biol. 19(4), $213(2018)$

53. F.F. Cruz, Z.D. Borg, M. Goodwin, D. Sokocevic, D.E. Wagner, A. Coffey, M. Antunes, K.L. Robinson, S.A. Mitsialis, S. Kourembanas, Systemic administration of human bone marrowderived mesenchymal stromal cell extracellular vesicles ameliorates aspergillus hyphal extract-induced allergic airway inflammation in immunocompetent mice. Stem Cells Transl. Med. 4(11), 1302-1316 (2015)

54. Z. Lanyu, H. Feilong, Emerging role of extracellular vesicles in lung injury and inflammation. Biomed. Pharmacother. 113, 108748 (2019)

55. E.I. Buzas, B. György, G. Nagy, A. Falus, S. Gay, Emerging role of extracellular vesicles in inflammatory diseases. Nat. Rev. Rheumatol. 10(6), 356-364 (2014)

56. A. Akbari, N. Jabbari, R. Sharifi, M. Ahmadi, A. Vahhabi, S.J. Seyedzadeh, M. Nawaz, S. Szafert, M. Mahmoodi, E. Jabbari, Free and hydrogel encapsulated exosome-based therapies in regenerative medicine, Life Sciences (2020) 117447.

57. A. Saghazadeh, N. Rezaei, Immune-epidemiological parameters of the novel coronavirus-a perspective. Expert. Rev. Clin. Immunol., 1-6 (2020)

58. K.S. Jones, Biomaterials as vaccine adjuvants. Biotechnol. Prog. 24(4), 807-814 (2008)

59. X. Chen, Y. Yan, M. Müllner, Y. Ping, J. Cui, K. Kempe, C. Cortez-Jugo, F. Caruso, Shape-dependent activation of cytokine secretion by polymer capsules in human monocyte-derived macrophages. Biomacromolecules 17(3), 1205-1212 (2016)

60. O. Veiseh, J.C. Doloff, M. Ma, A.J. Vegas, H.H. Tam, A.R. Bader, J. Li, E. Langan, J. Wyckoff, W.S. Loo, Size-and shapedependent foreign body immune response to materials implanted in rodents and non-human primates. Nat. Mater. 14(6), 643-651 (2015)

61. A.J. Miller, J.R. Spence, In vitro models to study human lung development, disease and homeostasis. Physiology (2017)

62. J.E. Nichols, J.A. Niles, S.P. Vega, J. Cortiella, Novel in vitro respiratory models to study lung development, physiology, pathology and toxicology. Stem Cell Res Ther 4(S1), S7 (2013)

63. A. Basiri, Z. Pazhouhnia, N. Beheshtizadeh, M. Hoseinpour, A. Saghazadeh, N. Rezaei, Regenerative medicine in COVID-19 treatment: real opportunities and range of promises. Stem Cell Rev. Rep., 1-13 (2020)

64. S.-J. Park, K.-M. Yu, Y.-I. Kim, S.-M. Kim, E.-H. Kim, S.-G. Kim, E.J. Kim, M.A.B. Casel, R. Rollon, S.-G. Jang, Antiviral efficacies of FDA-approved drugs against SARS-CoV-2 infection in Ferrets. Mbio 11(3) (2020)

65. J. Berg, T. Hiller, M.S. Kissner, T.H. Qazi, G.N. Duda, A.C. Hocke, S. Hippenstiel, L. Elomaa, M. Weinhart, C. Fahrenson, Optimization of cell-laden bioinks for 3D bioprinting and efficient infection with influenza A virus. Sci. Rep. 8(1), 1-13 (2018)

66. A. Antoshin, S. Churbanov, N. Minaev, D. Zhang, Y. Zhang, A. Shpichka, P. Timashev, LIFT-bioprinting, is it worth it? Bioprinting 15, e00052 (2019)

67. N. Ashammakhi, A. Hasan, O. Kaarela, B. Byambaa, A. Sheikhi, A.K. Gaharwar, A. Khademhosseini, Advancing Frontiers in Bone Bioprinting. Adv Healthc Mater 8(7), e1801048 (2019)

68. R. Bhowmick, T. Derakhshan, Y. Liang, J. Ritchey, L. Liu, H. Gappa-Fahlenkamp, A three-dimensional human tissue- engineered lung model to study influenza A infection. Tissue Eng. A 24(19-20), 1468-1480 (2018)

69. R. Koban, M. Neumann, A. Daugs, O. Bloch, A. Nitsche, S. Langhammer, H. Ellerbrok, A novel three-dimensional cell culture method enhances antiviral drug screening in primary human cells. Antivir. Res. 150, 20-29 (2018)

70. A. Shpichka, D. Osipova, Y. Efremov, P. Bikmulina, N. Kosheleva, M. Lipina, E.A. Bezrukov, R.B. Sukhanov, A.B. Solovieva, M. Vosough, fibrin-based bioinks: new tricks from an old dog. International Journal of Bioprinting 6(3) (2020)

71. V.A. Kornev, E.A. Grebenik, A.B. Solovieva, R.I. Dmitriev, P.S. Timashev, Hydrogel-assisted neuroregeneration approaches towards brain injury therapy: a state-of-the-art review. Computational and structural biotechnology journal 16, 488-502 (2018)

72. A. Shpichka, P. Konarev, Y.M. Efremov, A. Kryukova, N. Aksenova, S. Kotova, A. Frolova, N. Kosheleva, O. Zhigalina, V. Yusupov, Digging deeper: structural background of PEGylated fibrin gels in cell migration and lumenogenesis. RSC Adv. 10(8), 4190-4200 (2020)

73. A. Erdem, M.A. Darabi, R. Nasiri, S. Sangabathuni, Y.N. Ertas, H. Alem, V. Hosseini, A. Shamloo, A.S. Nasr, S. Ahadian, M.R. Dokmeci, A. Khademhosseini, N. Ashammakhi, 3D bioprinting of oxygenated cell-laden gelatin methacryloyl constructs. Adv Healthc Mater 9(15), e1901794 (2020)

74. N. Ashammakhi, S. Ahadian, C. Xu, H. Montazerian, H. Ko, R. Nasiri, N. Barros, A. Khademhosseini, Bioinks and bioprinting technologies to make heterogeneous and biomimetic tissue constructs. Mater. Today Bio. 1, 100008 (2019)

75. J. He, X. Zhang, X. Xia, M. Han, F. Li, C. Li, Y. Li, D. Gao, Organoid technology for tissue engineering. J. Mol. Cell Biol. (2020)

76. K. Ettayebi, S.E. Crawford, K. Murakami, J.R. Broughman, U. Karandikar, V.R. Tenge, F.H. Neill, S.E. Blutt, X.-L. Zeng, L. Qu, Replication of human noroviruses in stem cell-derived human enteroids. Science 353(6306), 1387-1393 (2016)

77. J. Zhou, C. Li, N. Sachs, M.C. Chiu, B.H.-Y. Wong, H. Chu, V.K.-M. Poon, D. Wang, X. Zhao, L. Wen, Differentiated human airway organoids to assess infectivity of emerging influenza virus. Proc. Natl. Acad. Sci. 115(26), 6822-6827 (2018)

78. L. Yang, Y. Han, B.E. Nilsson-Payant, V. Gupta, P. Wang, X. Duan, X. Tang, J. Zhu, Z. Zhao, F. Jaffré, A human pluripotent stem cell-based platform to study SARS-CoV-2 tropism and model virus infection in human cells and organoids. Cell stem cell 27(1), 125-136. e7 (2020)

79. V. Monteil, H. Kwon, P. Prado, A. Hagelkrüys, R.A. Wimmer, M. Stahl, A. Leopoldi, E. Garreta, C.H. Del Pozo, F. Prosper, in Cell. Inhibition of SARS-CoV-2 infections in engineered human tissues using clinical-grade soluble human ACE2 (2020)

80. H. Liu, Y. Wang, K. Cui, Y. Guo, X. Zhang, J. Qin, Advances in hydrogels in organoids and organs-on-a-chip. Adv. Mater. 31(50), 1902042 (2019)

81. J. Huang, Y. Jiang, Y. Ren, Y. Liu, X. Wu, Z. Li, J. Ren, Biomaterials and biosensors in intestinal organoid culture, a progress review. J. Biomed. Mater. Res. A 108(7), 1501-1508 (2020)

82. E. Jabbari, Challenges for natural hydrogels in tissue engineering. Gels 5(2), 30 (2019)

83. J. Zhu, Bioactive modification of poly (ethylene glycol) hydrogels for tissue engineering. Biomaterials 31(17), 4639-4656 (2010)

84. N. Gjorevski, M.P. Lutolf, Synthesis and characterization of welldefined hydrogel matrices and their application to intestinal stem cell and organoid culture. Nat. Protoc. 12(11), 2263-2274 (2017)

85. R. Cruz-Acuña, M. Quirós, A.E. Farkas, P.H. Dedhia, S. Huang, D. Siuda, V. García-Hernández, A.J. Miller, J.R. Spence, A. Nusrat, Synthetic hydrogels for human intestinal organoid 
generation and colonic wound repair. Nat. Cell Biol. 19(11), 1326-1335 (2017)

86. M.M. Capeling, M. Czerwinski, S. Huang, Y.-H. Tsai, A. Wu, M.S. Nagy, B. Juliar, N. Sundaram, Y. Song, W.M. Han, Nonadhesive alginate hydrogels support growth of pluripotent stem cell-derived intestinal organoids. Stem cell reports 12(2), 381-394 (2019)

87. N. Sachs, A. Papaspyropoulos, D.D. Zomer-van Ommen, I. Heo, L. Böttinger, D. Klay, F. Weeber, G. Huelsz-Prince, N. Iakobachvili, G.D. Amatngalim, Long-term expanding human airway organoids for disease modeling. EMBO J. 38(4), e100300 (2019)

88. A.A. Salahudeen, S.S. Choi, A. Rustagi, J. Zhu, V. van Unen, S.M. de la O, R.A. Flynn, M. Margalef-Català, A.J.M. Santos, J. Ju, A. Batish, T. Usui, G.X.Y. Zheng, C.E. Edwards, L.E. Wagar, V. Luca, B. Anchang, M. Nagendran, K. Nguyen, D.J. Hart, J.M. Terry, P. Belgrader, S.B. Ziraldo, T.S. Mikkelsen, P.B. Harbury, J.S. Glenn, K.C. Garcia, M.M. Davis, R.S. Baric, C. Sabatti, M.R. Amieva, C.A. Blish, T.J. Desai, C.J. Kuo, Progenitor identification and SARS-CoV-2 infection in human distal lung organoids. Nature (2020)

89. A. Sundarakrishnan, Y. Chen, L.D. Black, B.B. Aldridge, D.L. Kaplan, Engineered cell and tissue models of pulmonary fibrosis. Adv. Drug Deliv. Rev. 129, 78-94 (2018)

90. A.Z. Mykytyn, T.I. Breugem, S. Riesebosch, D. Schipper, P.B. van den Doel, R. Rottier, M.M. Lamers, B.L. Haagmans, in bioRxiv. The SARS-CoV-2 multibasic cleavage site facilitates early serine protease-mediated entry into organoid-derived human airway cells (2020)

91. M. Porotto, M. Ferren, Y.-W. Chen, Y. Siu, N. Makhsous, B. Rima, T. Briese, A. Greninger, H.-W. Snoeck, A. Moscona, Authentic modeling of human respiratory virus infection in human pluripotent stem cell-derived lung organoids. MBio 10(3) (2019)

92. G.G. Giobbe, F. Bonfante, E. Zambaiti, O. Gagliano, B.C. Jones, C. Luni, C. Laterza, S. Perin, H.T. Stuart, M. Pagliari, SARS$\mathrm{CoV}-2$ infection and replication in human fetal and pediatric gastric organoids. bioRxiv (2020)

93. M. Beld, R. Minnaar, J. Weel, C. Sol, M. Damen, H. van der Avoort, P. Wertheim-van Dillen, A. van Breda, R. Boom, Highly sensitive assay for detection of enterovirus in clinical specimens by reverse transcription-PCR with an armored RNA internal control. J. Clin. Microbiol. 42(7), 3059-3064 (2004)

94. H. Zhu, Z. Fohlerová, J. Pekárek, E. Basova, P. Neužil, Recent advances in lab-on-a-chip technologies for viral diagnosis. Biosens. Bioelectron. 153, 112041 (2020)

95. A. Bein, W. Shin, S. Jalili-Firoozinezhad, M.H. Park, A. Sontheimer-Phelps, A. Tovaglieri, A. Chalkiadaki, H.J. Kim, D.E. Ingber, Microfluidic organ-on-a-chip models of human intestine. Cellular and molecular gastroenterology and hepatology 5(4), 659-668 (2018)

96. R. Villenave, S.Q. Wales, T. Hamkins-Indik, E. Papafragkou, J.C. Weaver, T.C. Ferrante, A. Bahinski, C.A. Elkins, M. Kulka, D.E. Ingber, Human gut-on-a-chip supports polarized infection of coxsackie B1 virus in vitro. PLoS One 12(2), e0169412 (2017)

97. N. Ashammakhi, K. Wesseling-Perry, A. Hasan, E. Elkhammas, Y.S. Zhang, Kidney-on-a-chip: untapped opportunities. Kidney Int. 94(6), 1073-1086 (2018)

98. Y. Guo, R. Luo, Y. Wang, P. Deng, M. Zhang, P. Wang, X. Zhang, K. Cui, T. Tao, Z. Li, Modeling SARS-CoV-2 infection in vitro with a human intestine-on-chip device. bioRxiv (2020)

99. N. Ashammakhi, R. Nasiri, N.R. Barros, P. Tebon, J. Thakor, M. Goudie, A. Shamloo, M.G. Martin, A. Khademhosseini, gut-on-achip: current progress and future opportunities. Biomaterials 255, 120196 (2020)

100. M. Zhang, P. Wang, R. Luo, Y. Wang, Z. Li, Y. Guo, Y. Yao, M. Li, T. Tao, W. Chen, Biomimetic human disease model of SARS-
CoV-2 induced lung injury and immune responses on organ chip system. Adv Sci 2002928 (2020)

101. D. Huh, D.C. Leslie, B.D. Matthews, J.P. Fraser, S. Jurek, G.A. Hamilton, K.S. Thorneloe, M.A. McAlexander, D.E. Ingber, A human disease model of drug toxicity-induced pulmonary edema in a lung-on-a-chip microdevice. Science translational medicine 4(159), 159ra147-159ra147 (2012)

102. M. Chung, A. Bernheim, X. Mei, N. Zhang, M. Huang, X. Zeng, J. Cui, W. Xu, Y. Yang, Z.A. Fayad, A. Jacobi, K. Li, S. Li, H. Shan, CT imaging features of 2019 novel coronavirus (2019NCoV). Radiology 295(1), 202-207 (2020)

103. T. Ai, Z. Yang, H. Hou, C. Zhan, C. Chen, W. Lv, Q. Tao, Z. Sun, L. Xia, Correlation of chest CT and RT-PCR testing for coronavirus disease 2019 (COVID-19) in China: a report of 1014 Cases. Radiology 296(2), E32-E40 (2020)

104. V. Poortahmasebi, M. Zandi, S. Soltani, S.M. Jazayeri, Clinical performance of RT-PCR and chest CT scan for Covid-19 diagnosis; a systematic review. Adv. J. Emergency Med. 4(2, S), 1-7 (2020)

105. A.M. Cheraghali, H. Abolghasemi, P. Eshghi, Management of COVID-19 Virus Infection by Convalescent Plasma. Iranian Journal of Allergy, Asthma and Immunology 19(May), 3-6 (2020)

106. A. Haveri, T. Smura, S. Kuivanen, P. Österlund, J. Hepojoki, N. Ikonen, M. Pitkäpaasi, S. Blomqvist, E. Rönkkö, A. Kantele, T. Strandin, H. Kallio-Kokko, L. Mannonen, M. Lappalainen, M. Broas, M. Jiang, L. Siira, M. Salminen, T. Puumalainen, J. Sane, M. Melin, O. Vapalahti, C. Savolainen-Kopra, Serological and molecular findings during SARS-CoV-2 infection: the first case study in Finland, January to February 2020. Eurosurveillance 25(11), 1-6 (2020)

107. M. Sharifi, A. Hasan, S. Haghighat, A. Taghizadeh, F. Attar, S.H. Bloukh, Z. Edis, M. Xue, S. Khan, M. Falahati, Rapid diagnostics of coronavirus disease 2019 in early stages using nanobiosensors: Challenges and opportunities. Talanta 223(P1), 121704-121704 (2021)

108. N.H.A. Ellah, Nanomedicine as a promising approach for diagnosis , treatment and prophylaxis against COVID-19. 15, 2085-2102 (2020)

109. H. Kim, M. Park, J. Hwang, J.H. Kim, D.-R. Chung, Development of label-free colorimetric assay for MERS-CoV Using, (2019).

110. P. Moitra, M. Alafeef, K. Dighe, M.B. Frieman, D. Pan, Selective naked-eye detection of SARS-CoV-2 mediated by N gene targeted antisense oligonucleotide capped plasmonic nanoparticles. ACS Nano 14(6), 7617-7627 (2020)

111. C. Huang, T. Wen, F.-j. Shi, X.-y. Zeng, Y.-j. Jiao, Rapid detection of IgM antibodies against the SARS-CoV - 2 virus via colloidal gold nanoparticle-based lateral-flow assay, (2020).

112. F. Patolsky, G. Zheng, O. Hayden, M. Lakadamyali, X. Zhuang, C.M. Lieber, Electrical detection of single viruses. Proc. Natl. Acad. Sci. U. S. A. 101(39), 14017-14022 (2004)

113. G. Seo, G. Lee, M.J. Kim, S.H. Baek, M. Choi, K.B. Ku, C.S. Lee, S. Jun, D. Park, H.G. Kim, S.J. Kim, J.O. Lee, B.T. Kim, E.C. Park, S.I. Kim, Rapid detection of COVID-19 causative virus (SARS-CoV-2) in human nasopharyngeal swab specimens using field-effect transistor-based biosensor. ACS Nano 14(4), 5135$5142(2020)$

114. W. Li, L. Liu, L. Chen, S. Shang, Evaluation of a commercial colloidal gold assay for detection of influenza A and B virus in children' $\mathrm{s}$ respiratory specimens evaluation of a commercial colloidal gold assay for detection of influenza A and B virus in children ' s. Fetal and Pediatric Pathology 39(2), 93-98 (2020)

115. F. Yang, Y. Xiao, B. Chen, L. Wang, F. Liu, H. Yao, N. Wu, H. Wu, Development of a colloidal gold - based immunochromatographic strip test using two monoclonal 
antibodies to detect H7N9 avian influenza virus. Virus Genes 56(3), 396-400 (2020)

116. F. Yang, Y. Li, X. Jin, Q. Xu, F. Cheng, X. Wang, Immunosensorbased rapid quantitative detection of Newcastle disease virus antibodies using innovative gold immunochromatographic assay, (2020) 1-7.

117. M. Yu, Y. Bao, M. Wang, H. Zhu, X. Wang, L. Xing, F. Chang, Y. Liu, M. Farooque, Y. Wang, X. Qi, C. Liu, Y. Zhang, H. Cui, K. Li, L. Gao, Q. Pan, X. Wang, Y. Gao, Development and application of a colloidal gold test strip for detection of avian leukosis virus. 1999, 427-435 (2019)

118. J. Yu, Y. Lin, Y. Cao, X. Li, D. Liao, Y. Ye, M. Pan, J. Ye, Y. Wei, L. Xiao, others, Development and application of a colloidal gold test strip for the rapid detection of the infectious laryngotracheitis virus. Poult. Sci. 99(5), 2407-2415 (2020)

119. B. Zhang, B.A. Pinsky, J.S. Ananta, S. Zhao, S. Arulkumar, H. Wan, M.K. Sahoo, J. Abeynayake, J.J. Waggoner, C. Hopes, others, Diagnosis of Zika virus infection on a nanotechnology platform. Nat. Med. 23(5), 548-550 (2017)

120. N. Gjorevski, B. Avignon, R. Gérard, L. Cabon, A.B. Roth, M. Bscheider, A. Moisan, Neutrophilic infiltration in organ-on-a-chip model of tissue inflammation. Lab Chip 20(18), 3365-3374 (2020)

121. S. Safdar, J. Lammertyn, D. Spasic, RNA-cleaving nazymes: the next big thing in Biosensing? Trends Biotechnol., 1-17 (2020)

122. Y.V. Gerasimova, D.M. Kolpashchikov, Nucleic acid detection using MNAzymes. Chem. Biol. 17(2), 104-106 (2010)

123. J. Gao, N. Shimada, A. Maruyama, MNAzyme-catalyzed nucleic acid detection enhanced by a cationic copolymer. Biomater. Sci. 3(5), 716-720 (2015)

124. O. Hanpanich, K. Saito, N. Shimada, A. Maruyama, One-step isothermal RNA detection with LNA-modified MNAzymes chaperoned by cationic copolymer. Biosens. Bioelectron. 165, 112383-112383 (2020)

125. S. Safdar, K. Ven, J. van Lent, B. Pavie, I. Rutten, A. Dillen, S. Munck, J. Lammertyn, D. Spasic, DNA-only, microwell-based bioassay for multiplex nucleic acid detection with single basepair resolution using MNAzymes. Biosens. Bioelectron. 152(January), 112017-112017 (2020)

126. M. Wang, A. Fu, B. Hu, Y. Tong, R. Liu, Z. Liu, J. Gu, B. Xiang, J. Liu, W. Jiang, G. Shen, W. Zhao, D. Men, Z. Deng, L. Yu, W. Wei, Y. Li, T. Liu, Nanopore targeted sequencing for the accurate and comprehensive detection of SARS-CoV-2 and other respiratory viruses. Small 16(32) (2020)

127. F.M. Batista, T. Stapleton, J.A. Lowther, V.G. Fonseca, R. Shaw, C. Pond, D.I. Walker, R. van Aerle, J. Martinez-Urtaza, whole genome sequencing of hepatitis A virus using a PCR-free singlemolecule nanopore sequencing approach. Front. Microbiol. 11(May), 1-9 (2020)

128. H. Takeda, T. Yamashita, Y. Ueda, A. Sekine, Exploring the hepatitis $\mathrm{C}$ virus genome using single molecule real-time sequencing. World J. Gastroenterol. 25(32), 4661-4672 (2019)

129. N. Ashammakhi, M.A. Darabi, I. Pountos, the dynamic cycle of future personalized and regenerative therapy. Journal of Craniofacial Surgery 30(3), 623-625 (2019)

130. W.C. Chou, W.P. Hu, Y.S. Yang, H.W.H. Chan, W.Y. Chen, Neutralized chimeric DNA probe for the improvement of GCrich RNA detection specificity on the nanowire field-effect transistor. Sci. Rep. 9(1), 1-10 (2019)

131. K. Dziabowska, E. Czaczyk, D. Nidzworski, Detection methods of human and animal influenza virus - current trends. Biosensors 8(4), 1-24 (2018)

132. M. Uhm, J.M. Lee, J. Lee, J.H. Lee, S. Choi, B.G. Park, D.M. Kim, S.J. Choi, H.S. Mo, Y.J. Jeong, D.H. Kim, Ultrasensitive electrical detection of hemagglutinin for point-of-care detection of influenza virus based on a CMP-NANA probe and top-down processed silicon nanowire field-effect transistors. Sensors (Switzerland) 19(20) (2019)

133. K.A. Malsagova, T.O. Pleshakova, R.A. Galiullin, I.D. Shumov, A.F. Kozlov, T.S. Romanova, V.P. Popov, A.V. Glukhov, V.A. Konev, A.I. Archakov, others, Nanowire aptamer-sensitized biosensor chips with gas plasma-treated surface for the detection of hepatitis C virus core antigen. Coatings 10(8), 753-753 (2020)

134. V.M. Generalov, O.V. Naumova, B.I. Fomin, S.A. P'yankov, I.V. Khlistun, A.S. Safatov, B.N. Zaitsev, E.G. Zaitseva, A.L. Aseev, Detection of ebola virus VP40 Protein using a nanowire SOI biosensor, optoelectronics, instrumentation and data processing. 55(6), 618-622 (2019)

135. A.K. Geim, K.S. Novoselov, The rise of graphene. World Scientific, 11-19 (2010)

136. G. Seo, G. Lee, M.J. Kim, S.-h. Baek, M. Choi, K.B. Ku, C.-s. Lee, S. Jun, D. Park, H.G. Kim, S.-j. Kim, J.-o. Lee, B.T. Kim, E.C. Park, S.I. Kim, Rapid detection of COVID-19 causative virus (SARS-CoV-2) in human nasopharyngeal swab specimens using field-effect transistor-based biosensor, (2020).

137. M. Shariati, M. Sadeghi, Ultrasensitive DNA biosensor for hepatitis B virus detection based on tin-doped WO 3 / In 2 O 3 heterojunction nanowire photoelectrode under laser amplification, (2020) 5367-5377.

138. F. Khosravi, N. Maryam, T. Sayeh, J. Marandi, M. Shariati, The highly sensitive impedimetric biosensor in label free approach for hepatitis B virus DNA detection based on tellurium doped $\mathrm{ZnO}$ nanowires. Appl. Phys. A 125(9), 1-8 (2019)

139. E.Y. Park, Electrical pulse-induced electrochemical biosensor for hepatitis E virus detection. Nat. Commun., 4-7 (2019)

140. A. Nsamela, Microfluidics for point-of-care diagnostic devices: a review. Elveflow (2020)

141. A. Bukreyev, E.W. Lamirande, U.J. Buchholz, L.N. Vogel, W.R. Elkins, M.S. Claire, B.R. Murphy, K. Subbarao, P.L. Collins, Since January 2020 Elsevier has created a COVID-19 resource centre with free information in English and Mandarin on the novel coronavirus COVID- 19. The COVID-19 resource centre is hosted on Elsevier Connect, the company ' s public news and information, (January) (2020)

142. A. Basiri, A. Heidari, M.F. Nadi, M.T.P. Fallahy, S.S Nezamabadi, M. Sedighi, A. Saghazadeh, N. Rezaei, Microfluidic devices for detection of RNA viruses. Rev. Med. Virol. 2020(April), 1-11 (2019)

143. Y. Gao, J. Pallister, F. Lapierre, G. Crameri, L.F. Wang, Y. Zhu, A rapid assay for Hendra virus IgG antibody detection and its titre estimation using magnetic nanoparticles and phycoerythrin. J. Virol. Methods 222, 170-177 (2015)

144. Y. Wang, Q. Ruan, Z.C. Lei, S.C. Lin, Z. Zhu, L. Zhou, C. Yang, Highly sensitive and automated surface enhanced raman scattering-based immunoassay for H5N1 detection with digital microfluidics. Anal. Chem. 90(8), 5224-5231 (2018)

145. X. Yu, Y. Xia, Y. Tang, W.L. Zhang, Y.T. Yeh, H. Lu, S.Y. Zheng, A nanostructured microfluidic immunoassay platform for highly sensitive infectious pathogen detection. Small 13(24), 1-12 (2017)

146. S. Tripathi, A. Agrawal, Blood plasma microfluidic device: aiming for the detection of COVID-19 antibodies using an onchip ELISA platform, Transactions of the Indian National Academy of. Engineering 5(2), 217-220 (2020)

147. Y. Xia, Y. Tang, X. Yu, Y. Wan, Y. Chen, H. Lu, S.Y. Zheng, Label-free virus capture and release by a microfluidic device integrated with porous silicon nanowire Forest. Small 13(6), 1-11 (2017)

148. P. Guo, C. Wei, Quantum dots for robust and simple assays using single particles in nanodevices. Nanomedicine: nanotechnology, biology, and medicine 2(1), 122-124 (2005) 
149. M.V. Palmer, T.C. Thacker, W. Waters, C. Gortázar, L.A. Corner, Mycobacterium bovis: a model pathogen at the interface of livestock, wildlife, and humans, Veterinary medicine international 2012 (2012).

150. P. Kumar, Y. Malik, B. Ganesh, S. Rahangdale, S. Saurabh, S. Natesan, A. Srivastava, K. Sharun, M. Yatoo, R. Tiwari, CRISPRCas system: an approach with potentials for COVID-19 diagnosis and therapeutics. Front. Cell. Infect. Microbiol. 10, 576875 (2020). https://doi.org/10.3389/fcimb

151. M. Wang, R. Zhang, J. Li, CRISPR/cas systems redefine nucleic acid detection: principles and methods. Biosens. Bioelectron. $112430(2020)$

152. S. Mahari, A. Roberts, D. Shahdeo, S. Gandhi, eCovSensultrasensitive novel in-house built printed circuit board based electrochemical device for rapid detection of nCovid-19 antigen, a spike protein domain 1 of SARS-CoV-2. bioRxiv (2020)

153. A. Djaileb, B. Charron, M.H. Jodaylami, V. Thibault, J. Coutu, K. Stevenson, S. Forest, L.S. Live, D. Boudreau, J.N. Pelletier, A rapid and quantitative serum test for SARS-CoV-2 antibodies with portable surface plasmon resonance sensing, (2020).

154. R. Hajian, S. Balderston, T. Tran, T. deBoer, J. Etienne, M. Sandhu, N.A. Wauford, J.Y. Chung, J. Nokes, M. Athaiya, J. Paredes, R. Peytavi, B. Goldsmith, N. Murthy, I.M. Conboy, K. Aran, Detection of unamplified target genes via CRISPR-Cas9 immobilized on a graphene field-effect transistor. Nature Biomed Eng 3(6), 427-437 (2019)

155. T. Zhang, Y. He, W. Xu, A. Ma, Y. Yang, K.-F. Xu, Clinical trials for the treatment of Coronavirus disease 2019 (COVID-19): a rapid response to urgent need. Sci. China Life Sci., 1-3 (2020)

156. F. Zhou, T. Yu, R. Du, G. Fan, Y. Liu, Z. Liu, J. Xiang, Y. Wang, B. Song, X. Gu, Clinical course and risk factors for mortality of adult inpatients with COVID-19 in Wuhan, China: a retrospective cohort study. Lancet (2020)

157. B. Huang, R. Ling, Y. Cheng, J. Wen, Y. Dai, W. Huang, S. Zhang, X. Lu, Y. Luo, Y.-Z. Jiang, Characteristics of the coronavirus disease 2019 and related therapeutic options, molecular therapy. Methods \& clinical development 18, 367 (2020)

158. J. Wang, Fast identification of possible drug treatment of coronavirus disease-19 (COVID-19) through computational drug repurposing study. J. Chem. Inf. Model. (2020)

159. L.-S. Wang, Y.-R. Wang, D.-W. Ye, Q.-Q. Liu, A review of the 2019 Novel Coronavirus (COVID-19) based on current evidence. Int. J. Antimicrob. Agents 2020, 105948

160. J. Stebbing, A. Phelan, I. Griffin, C. Tucker, O. Oechsle, D. Smith, P. Richardson, COVID-19: combining antiviral and antiinflammatory treatments. Lancet Infect. Dis. 20(4), 400-402 (2020)

161. M. Zheng, L. Song, Novel antibody epitopes dominate the antigenicity of spike glycoprotein in SARS-CoV-2 compared to SARSCoV. Cell. Mol. Immunol. 17(5), 536-538 (2020)

162. A.A. Elfiky, Anti-HCV, nucleotide inhibitors, repurposing against COVID-19. Life Sci. 117477 (2020)

163. C. Wu, Y. Liu, Y. Yang, P. Zhang, W. Zhong, Y. Wang, Q. Wang, Y. Xu, M. Li, X. Li, Analysis of therapeutic targets for SARSCoV-2 and discovery of potential drugs by computational methods. Acta Pharm. Sin. B (2020)

164. M. Wang, R. Cao, L. Zhang, X. Yang, J. Liu, M. Xu, Z. Shi, Z. $\mathrm{Hu}, \mathrm{W}$. Zhong, G. Xiao, Remdesivir and chloroquine effectively inhibit the recently emerged novel coronavirus (2019-nCoV) in vitro. Cell Res. 30(3), 269-271 (2020)

165. B.R. Beck, B. Shin, Y. Choi, S. Park, K. Kang, Predicting commercially available antiviral drugs that may act on the novel coronavirus (SARS-CoV-2) through a drug-target interaction deep learning model. Computational and structural biotechnology journal (2020)
166. A. Wu, Y. Peng, B. Huang, X. Ding, X. Wang, P. Niu, J. Meng, Z. Zhu, Z. Zhang, J. Wang, Genome composition and divergence of the novel coronavirus (2019-nCoV) originating in China. Cell Host Microbe (2020)

167. S.U.R. Cheema, M.S. Rehman, G. Hussain, S.S. Cheema, N. Gilani, Efficacy and tolerability of sofosbuvir and daclatasvir for treatment of hepatitis $\mathrm{C}$ genotype $1 \& 3$ in patients undergoing hemodialysis-a prospective interventional clinical trial. BMC Nephrol. 20, 438(1) (2019)

168. R.C. Group, Dexamethasone in hospitalized patients with Covid19 - preliminary report. N. Engl. J. Med. (2020)

169. F.-D. Cojocaru, D. Botezat, I. Gardikiotis, C.-M. Uritu, G. Dodi, L. Trandafir, C. Rezus, E. Rezus, B.-I. Tamba, C.-T. Mihai, Nanomaterials designed for antiviral drug delivery transport across biological barriers. Pharmaceutics 12, 171(2) (2020)

170. J.R. Giudicessi, P.A. Noseworthy, P.A. Friedman, M.J. Ackerman, Urgent guidance for navigating and circumventing the QTc-prolonging and torsadogenic potential of possible pharmacotherapies for coronavirus disease 19 (COVID-19), Mayo Clinic Proceedings (Elsevier, 2020)

171. Y. Chan, S.W. Ng, M. Mehta, K. Anand, S.K. Singh, G. Gupta, D.K. Chellappan, K. Dua, Advanced drug delivery systems can assist in managing influenza virus infection: a hypothesis. Med. Hypotheses 144, 110298 (2020)

172. A. Khalaj-Hedayati, C.L.L. Chua, P. Smooker, K.W. Lee, Nanoparticles in influenza subunit vaccine development: immunogenicity enhancement. Influenza Other Respir. Viruses 14(1), 92-101 (2020)

173. Y. Wang, L. Deng, S.-M. Kang, B.-Z. Wang, Universal influenza vaccines: from viruses to nanoparticles. Expert review of vaccines 17(11), 967-976 (2018)

174. A.S. Timin, A.R. Muslimov, A.V. Petrova, K.V. Lepik, M.V. Okilova, A.V. Vasin, B.V. Afanasyev, G.B. Sukhorukov, Hybrid inorganic-organic capsules for efficient intracellular delivery of novel siRNAs against influenza A (H1N1) virus infection. Sci. Rep. 7(1), 1-12 (2017)

175. Q. He, Y. Cui, J. Li, Molecular assembly and application of biomimetic microcapsules. Chem. Soc. Rev. 38(8), 2292-2303 (2009)

176. B. Vellingiri, K. Jayaramayya, M. Iyer, A. Narayanasamy, V. Govindasamy, B. Giridharan, S. Ganesan, A. Venugopal, D. Venkatesan, H. Ganesan, COVID-19: a promising cure for the global panic. Sci. Total Environ. 138277 (2020)

177. J.D. Brain, Inhalation, deposition, and fate of insulin and other therapeutic proteins. Diabetes technology \& therapeutics 9(S1), S-4-S-15 (2007)

178. J. Wang, P. Li, Y. Yu, Y. Fu, H. Jiang, M. Lu, Z. Sun, S. Jiang, L. Lu, M.X. Wu, Pulmonary surfactant-biomimetic nanoparticles potentiate heterosubtypic influenza immunity. Science 367(6480) (2020)

179. X. Wang, V. Parvathaneni, S.K. Shukla, D.D. Kanabar, A. Muth, V. Gupta, Cyclodextrin complexation for enhanced stability and non-invasive pulmonary delivery of resveratrol — applications in non-small cell lung cancer treatment. AAPS PharmSciTech 21(5), $1-14(2020)$

180. A.K. Thakur, D.K. Chellappan, K. Dua, M. Mehta, S. Satija, I. Singh, Patented therapeutic drug delivery strategies for targeting pulmonary diseases. Expert opinion on therapeutic patents 30(5), 375-387 (2020)

181. X. Tong, W. Pan, T. Su, M. Zhang, W. Dong, X. Qi, Recent advances in natural polymer-based drug delivery systems. React. Funct. Polym. 148, 104501 (2020)

182. D.T. Pham, A. Chokamonsirikun, V. Phattaravorakarn, W. Tiyaboonchai, Polymeric micelles for pulmonary drug delivery: a comprehensive review. J. Mater. Sci. 56(3), 2016-2036 (2021) 
183. C. Liu, Q. Zhou, Y. Li, L.V. Garner, S.P. Watkins, L.J. Carter, J. Smoot, A.C. Gregg, A.D. Daniels, S. Jervey, Research and development on therapeutic agents and vaccines for COVID-19 and related human coronavirus diseases (ACS Publications, 2020)

184. N. Kumar, D. Sood, P.J. van der Spek, H.S. Sharma, R. Chandra, Molecular binding mechanism and pharmacology comparative analysis of noscapine for repurposing against SARS-CoV-2 protease. J. Proteome Res. 19(11), 4678-4689 (2020)

185. F. Langellotto, B.T. Seiler, J. Yu, M.J. Cartwright, D. White, C. Yeager, M. Super, E.J. Doherty, D.H. Barouch, D.J. Mooney, A rapidly adaptable biomaterial vaccine for SARS-CoV-2. bioRxiv (2020)

186. K.A. Hajj, J.R. Melamed, N. Chaudhary, N.G. Lamson, R.L. Ball, S.S. Yerneni, K.A. Whitehead, A potent branched-tail lipid nanoparticle enables multiplexed mRNA delivery and gene editing in vivo. Nano Lett. (2020)

187. N. Lurie, M. Saville, R. Hatchett, J. Halton, Developing Covid-19 vaccines at pandemic speed. N. Engl. J. Med. 382(21), 1969-1973 (2020)

188. S. Rauch, E. Jasny, K.E. Schmidt, B. Petsch, New vaccine technologies to combat outbreak situations. Front. Immunol. 9, 1963 (2018)

189. L. Dai, T. Zheng, K. Xu, Y. Han, L. Xu, E. Huang, Y. An, Y. Cheng, S. Li, M. Liu, A universal design of betacoronavirus vaccines against COVID-19, MERS, and SARS. Cell 182(3), 722733. e11 (2020)

190. A. Koirala, Y.J. Joo, A. Khatami, C. Chiu, P.N. Britton, Vaccines for COVID-19: the current state of play. Paediatr. Respir. Rev. 35, 43-49 (2020)

191. Anonymous, Pfizer-BioNTech COVID-19 Vaccine. US Food and Drug Administration (Accessed December 29).

192. Anonymous, Moderna COVID-19 Vaccine. US Food and Drug Administration. (Accessed December 29).

193. Z. Liang, H. Zhu, X. Wang, B. Jing, Z. Li, X. Xia, H. Sun, Y. Yang, W. Zhang, L. Shi, Adjuvants for coronavirus vaccines. Front. Immunol. 11, 2896 (2020)

194. T. Brown, C. Nigoghossian, D. Zidar, J. Haythe, D. Brodie, J. Beckman, A. Kirtane, in ru. G. Stone, stopcovid19. com (1920)

195. K. Clerkin, J. Fried, J. Raikhelkar, G. Sayer, J. Griffin, A. Masoumi, D. Coronavirus, et al., (COVID-19) and cardiovascular disease. Circulation (2019)

196. G. COVID, Thrombosis Collaborative Group Bikdeli B, Madhavan MV, Gupta A, Pharmacological agents targeting thromboinflammation in COVID-19: review and implications for future research. Thromb. Haemost. 10 (2020)

197. F. Marongiu, E. Grandone, D. Barcellona, Pulmonary thrombosis in 2019-nCoV pneumonia? J. Thromb. Haemost. (2020)

198. S. Cui, S. Chen, X. Li, S. Liu, F. Wang, Prevalence of venous thromboembolism in patients with severe novel coronavirus pneumonia. J. Thromb. Haemost. (2020)

199. F.A. Klok, M. Kruip, N. Van Der Meer, M. Arbous, D. Gommers, K. Kant, F. Kaptein, J. van Paassen, M. Stals, M. Huisman, Confirmation of the high cumulative incidence of thrombotic complications in critically ill ICU patients with COVID-19: an updated analysis. Thromb. Res. (2020)

200. J.M. Tsutsui, F. Xie, M. Cano, J. Chomas, P. Phillips, S.J. Radio, J. Lof, T.R. Porter, Detection of retained microbubbles in carotid arteries with real-time low mechanical index imaging in the setting of endothelial dysfunction. J. Am. Coll. Cardiol. 44(5), 10361046 (2004)

201. N. Kipshidze, P. Iversen, T.R. Porter, N. Kipshidze, F. Siddiqui, G. Dangas, J. Fareed, Targeted, site-specific, delivery vehicles of therapeutics for COVID-19 patients. Brief Review, Clinical and Applied Thrombosis/Hemostasis 26, 1076029620954911 (2020)

202. S.-n. Nishimura, T. Ueda, S. Kobayashi, M. Tanaka, Silsesquioxane/Poly (2-methoxyethyl acrylate) Hybrid with both antithrombotic and endothelial cell adhesive properties. ACS Appl Polym Mater (2020)

203. M. Noah, G. Peek, S. Finney, Referral to an extracorporeal membrane oxygenation center and mortality among patients with severe 2009 influenza A (H1N1). JAMA. 306, 1659-1668 (2011)

204. M. James, L. Marguerite, Z. Tomasz, B. James, Pharmacologic treatments for coronavirus disease 2019 (COVID-19). JAMA 323(18), 1824-1836 (2020)

205. L.M. Walker, D.R. Burton, Passive immunotherapy of viral infections:'super-antibodies' enter the fray. Nat. Rev. Immunol. 18, 297(5) (2018)

206. Y. Singh, G. Gupta, S. Satija, K. Pabreja, D.K. Chellappan, K. Dua, COVID-19 transmission through host cell directed network of GPCR. Drug Dev. Res. (2020)

207. Y. Kim, R. Jedrzejczak, N.I. Maltseva, M. Wilamowski, M. Endres, A. Godzik, K. Michalska, A. Joachimiak, Crystal structure of Nsp15 endoribonuclease NendoU from SARS-CoV-2. Protein Sci. (2020)

208. J. Nieto-Torres, C. Verdiá-Bá guena, J.M. Jimenez-Guardeño, J.A. Regla-Nava, C. Castaño-Rodriguez, R. Fernandez-Delgado, et al., Severe acute respiratory syndrome coronavirus $\mathrm{E}$ protein transports calcium ions and activates the NLRP3 inflammasome. Virology 485(Supplement C), 330-339 (2015)

209. M. Mehta, P. Prasher, M. Sharma, M.D. Shastri, N. Khurana, M. Vyas, H. Dureja, G. Gupta, K. Anand, S. Satija, Advanced drug delivery systems can assist in targeting coronavirus disease (COVID-19): A hypothesis. Med. Hypotheses 144, 110254 (2020)

210. F. Canta, R. Marrone, S. Bonora, A. D'Avolio, M. Sciandra, A. Sinicco, F.G. De Rosa, G. Di Perri, Pharmacokinetics and hepatotoxicity of lopinavir/ritonavir in non-cirrhotic HIV and hepatitis $\mathrm{C}$ virus (HCV) co-infected patients. J. Antimicrob. Chemother. 55(2), 280-281 (2005)

211. K. Lee, E. Silva, D. Mooney, JR Soc. Interface 8(55), 153-170 (2011)

212. E.T. Pashuck, M.M. Stevens, Designing regenerative biomaterial therapies for the clinic. Science translational medicine 4(160), 160sr4-160sr4 (2012)

213. F. van Dijk, N. Teekamp, L. Beljaars, E. Post, J. Zuidema, R. Steendam, Y. Kim, H. Frijlink, D. Schuppan, K. Poelstra, Pharmacokinetics of a sustained release formulation of PDGF $\beta$ receptor directed carrier proteins to target the fibrotic liver. J. Control. Release 269, 258-265 (2018)

214. W. Dai, B. Zhang, X.-M. Jiang, H. Su, J. Li, Y. Zhao, X. Xie, Z. Jin, J. Peng, F. Liu, Structure-based design, synthesis and biological evaluation of peptidomimetic aldehydes as a novel series of antiviral drug candidates targeting the SARS-CoV-2 main protease. bioRxiv (2020)

215. J. Jiang, K. Huo, Z. Wu, S. Chen, S. Pu, Z. Yu, X. Liu, P.K. Chu, Silicon-induced DNA damage pathway and its modulation by titanium plasma immersion ion implantation. Biomaterials 29(5), 544-550 (2008)

216. D. Raghuwanshi, V. Mishra, D. Das, K. Kaur, M.R. Suresh, Dendritic cell targeted chitosan nanoparticles for nasal DNA immunization against SARS CoV nucleocapsid protein. Mol. Pharm. 9(4), 946-956 (2012)

217. H.-Q. Mao, K. Roy, V.L. Troung-Le, K.A. Janes, K.Y. Lin, Y. Wang, J.T. August, K.W. Leong, Chitosan-DNA nanoparticles as gene carriers: synthesis, characterization and transfection efficiency. Journal of controlled release 70(3), 399-421 (2001)

218. N. Ashammakhi, O. Kaarela, Stimuli-Responsive Biomaterials: Next Wave. J Craniofac Surg 28(7), 1647-1648 (2017)

219. Y. Lu, A.A. Aimetti, R. Langer, Z. Gu, Bioresponsive materials. Nat. Rev. Mater. 2(1), 16075 (2016)

220. J.S. Kahn, A. Trifonov, A. Cecconello, W. Guo, C. Fan, I. Willner, Integration of switchable DNA-based hydrogels with surfaces by 
the hybridization chain reaction. Nano Lett. 15(11), 7773-7778 (2015)

221. E. Heitzer, P. Ulz, J.B. Geigl, Circulating tumor DNA as a liquid biopsy for cancer. Clin. Chem. 61(1), 112-123 (2015)

222. M.A. English, L.R. Soenksen, R.V. Gayet, H. de Puig, N.M. Angenent-Mari, A.S. Mao, P.Q. Nguyen, J.J. Collins, Programmable CRISPR-responsive smart materials. Science 365(6455), 780-785 (2019)

223. A. Paunel-Görgülü, M. Wacker, M. El Aita, S. Hassan, G. Schlachtenberger, A. Deppe, Y.-H. Choi, E. Kuhn, T.O. Mehler, T. Wahlers, cfDNA correlates with endothelial damage after cardiac surgery with prolonged cardiopulmonary bypass and amplifies NETosis in an intracellular TLR9-independent manner. Sci. Rep. 7(1), 1-13 (2017)

224. Y.Y. Lee, H.H. Park, W. Park, H. Kim, J.G. Jang, K.S. Hong, J.Y. Lee, H.S. Seo, D.H. Na, T.-H. Kim, Long-acting nanoparticulate DNase-1 for effective suppression of SARSCoV-2-mediated neutrophil activities and cytokine storm. Biomaterials 120389 (2020)

225. T.A. Pimentel, Z. Yan, S.A. Jeffers, K.V. Holmes, R.S. Hodges, P. Burkhard, Peptide nanoparticles as novel immunogens: design and analysis of a prototypic severe acute respiratory syndrome vaccine. Chem. Biol. Drug Des. 73(1), 53-61 (2009)

226. B. Shan, Y.Y. Broza, W. Li, Y. Wang, S. Wu, Z. Liu, J. Wang, S. Gui, L. Wang, Z. Zhang, W. Liu, S. Zhou, W. Jin, Q. Zhang, D. Hu, L. Lin, Q. Zhang, W. Li, J. Wang, H. Liu, Y. Pan, H. Haick, Multiplexed nanomaterial-based sensor array for detection of COVID-19 in exhaled breath. ACS Nano 14(9), 12125-12132 (2020)

227. F. Zhang, O.O. Abudayyeh, J.S. Gootenberg, C. Sciences, L. Mathers, A protocol for detection of COVID-19 using CRISPR diagnostics. Bioarchive, 1-8 (2020)

228. R.M. Torrente-Rodríguez, H. Lukas, J. Tu, J. Min, Y. Yang, C. Xu, H.B. Rossiter, W. Gao, SARS-CoV-2 RapidPlex: A Graphene-Based Multiplexed Telemedicine Platform for Rapid and Low-Cost COVID-19 Diagnosis and Monitoring. Matter 3(6), 1981-1998 (2020)

229. J. Jiao, C. Duan, L. Xue, Y. Liu, W. Sun, Y. Xiang, DNA nanoscaffold-based SARS-CoV-2 detection for COVID-19 diagnosis. Biosens. Bioelectron. 167, 112479 (2020)

230. M.G.S. Borba, F.F.A. Val, V.S. Sampaio, M.A.A. Alexandre, G.C. Melo, M. Brito, M.P.G. Mourão, J.D. Brito-Sousa, D. Baía-da-Silva, M.V.F. Guerra, Effect of high vs low doses of chloroquine diphosphate as adjunctive therapy for patients hospitalized with severe acute respiratory syndrome coronavirus 2
(SARS-CoV-2) infection: a randomized clinical trial. JAMA Netw. Open 3(4), e208857-e208857 (2020)

231. G. Lentini, M.M. Cavalluzzi, S. Habtemariam, COVID-19, chloroquine repurposing, and cardiac safety concern: Chirality might help. Molecules 25(8), 1834 (2020)

232. N.J. Cho, J.S. Glenn, Materials science approaches in the development of broad-spectrum antiviral therapies. Nat. Mater., 1-4 (2020)

233. X. Li, S. Chang, G. Du, Y. Li, J. Gong, M. Yang, Z. Wei, Encapsulation of azithromycin into polymeric microspheres by reduced pressure-solvent evaporation method. Int. J. Pharm. 433(1-2), 79-88 (2012)

234. R. Zang, M.F.G. Castro, B.T. McCune, Q. Zeng, P.W. Rothlauf, N.M. Sonnek, Z. Liu, K.F. Brulois, X. Wang, H.B. Greenberg, TMPRSS2 and TMPRSS4 promote SARS-CoV-2 infection of human small intestinal enterocytes. Sci. Immunol. 5(47) (2020)

235. J. Zhou, C. Li, X. Liu, M.C. Chiu, X. Zhao, D. Wang, Y. Wei, A. Lee, A.J. Zhang, H. Chu, Infection of bat and human intestinal organoids by SARS-CoV-2. Nat. Med., 1-7 (2020)

236. M.M. Lamers, J. Beumer, J. van der Vaart, K. Knoops, J. Puschhof, T.I. Breugem, R.B. Ravelli, J.P. van Schayck, A.Z. Mykytyn, H.Q. Duimel, SARS-CoV-2 productively infects human gut enterocytes. Science (2020)

237. M.A. Barry, Q. Wang, K.M. Jones, M.J. Heffernan, M.H. Buhaya, C.M. Beaumier, B.P. Keegan, B. Zhan, E. Dumonteil, M.E. Bottazzi, A therapeutic nanoparticle vaccine against Trypanosoma cruzi in a BALB/c mouse model of Chagas disease. Human vaccines \& immunotherapeutics 12(4), 976-987 (2016)

238. T. Jiang, B. Singh, H.-S. Li, Y.-K. Kim, S.-K. Kang, J.-W. Nah, Y.-J. Choi, C.-S. Cho, Targeted oral delivery of BmpB vaccine using porous PLGA microparticles coated with $\mathrm{M}$ cell homing peptide-coupled chitosan. Biomaterials 35(7), 2365-2373 (2014)

239. J. Kim, W.A. Li, Y. Choi, S.A. Lewin, C.S. Verbeke, G. Dranoff, D.J. Mooney, Injectable, spontaneously assembling, inorganic scaffolds modulate immune cells in vivo and increase vaccine efficacy. Nat. Biotechnol. 33(1), 64-72 (2015)

240. Y. Wu, W. Wei, M. Zhou, Y. Wang, J. Wu, G. Ma, Z. Su, Thermal-sensitive hydrogel as adjuvant-free vaccine delivery system for H5N1 intranasal immunization. Biomaterials 33(7), 2351$2360(2012)$

241. S. Duffy, Why are RNA virus mutation rates so damn high? PLoS Biol. 16(8), e3000003 (2018)

242. S.E. Park, A. Georgescu, D. Huh, Organoids-on-a-chip. Science 364(6444), 960-965 (2019) 